\title{
The Particle has Landed-Characterizing the Fate of Inhaled Pharmaceuticals
}

\author{
John S. Patton, Ph.D.,, Joseph D. Brain, Ph.D., Lee A. Davies, Ph.D., ${ }^{3}$ Jennifer Fiegel, Ph.D., \\ Mark Gumbleton, Ph.D., Kwang-Jin Kim, Ph.D., ${ }^{6}$ Masahiro Sakagami, Ph.D., \\ Rita Vanbever, Ph.D., ${ }^{8}$ and Carsten Ehrhardt, Ph.D. ${ }^{9}$
}

\begin{abstract}
Although there is a modest body of literature on the absorption of inhaled pharmaceuticals by normal lungs and some limited information from diseased lungs, there is still a surprising lack of mechanistic knowledge about the details of the processes involved. Where are molecules absorbed, what mechanisms are involved, how well are different lung regions penetrated, what are the determinants of metabolism and dissolution, and how best can one retard the clearance of molecules deposited in the lung or induce intracellular uptake by lung cells? Some general principles are evident: (1) small hydrophobic molecules are absorbed very fast (within tens of seconds) usually with little metabolism; (2) small hydrophilic molecules are absorbed fast (within tens of minutes), again with minimal metabolism; (3) very low water solubility of the drug can retard absorption; (4) peptides are rapidly absorbed but are significantly metabolized unless chemically protected against peptidases; (5) larger proteins are more slowly absorbed with variable bioavailabilities; and 6) insulin seems to be best absorbed distally in the lungs while certain antibodies appear to be preferentially absorbed in the upper airways. For local lung disease applications, and some systemic applications as well, many small molecules are absorbed much too fast for convenient and effective therapies. For systemic delivery of peptides and proteins, absorption may sometimes be too fast. Bioavailabilities are often too low for cost-effective and reliable treatments. A better understanding of the determinants of pulmonary drug dissolution, absorption, metabolism, and how to target specific regions and/or cells in the lung will enable safer and more effective inhaled medicines in the future.
\end{abstract}

Key words: aerosol deposition, drug absorption, lung clearance, lung disease, macrophages, particle dissolution, peptides, proteins, pulmonary pharmacokinetics, gene delivery, RNAi

\section{Introduction}

T HE FATE OF INHALED MEDicines is far from being well understood. The paradigm that successful generation of aerosols with a prominent fine particle fraction is sufficient to ensure excellent pulmonary absorption or effectiveness is increasingly being challenged.
What is the importance of lung fluids for the dissolution of inhaled medicines as well as their transport into and across the lung tissue for local and systemic absorption, respectively? Indeed, what is the amount and composition of airway and alveolar lining fluids? Does surfactant-assisted lateral spreading of inhaled drugs/particles affect absorption and bioavailability? Can particles penetrate the mucus

\footnotetext{
${ }^{1}$ Dance Pharmaceuticals, San Francisco, California.

${ }^{2}$ Harvard School of Public Health, Boston, Massachusetts.

${ }^{3}$ Gene Medicine Group, University of Oxford, Oxford, United Kingdom.

${ }^{4}$ Colleges of Pharmacy and Engineering, University of Iowa, Iowa City, Iowa.

${ }^{5}$ Welsh School of Pharmacy, Cardiff University, Cardiff, Wales, United Kingdom.

${ }^{6}$ Will Rogers Institute Pulmonary Research Center, Keck School of Medicine, University of Southern California, Los Angeles, California.

${ }^{7}$ School of Pharmacy, Virginia Commonwealth University, Richmond, Virginia.

${ }^{8}$ Unité de Pharmacie Galénique, Louvain Drug Research Institute, Université catholique de Louvain, Brussels, Belgium.

${ }^{9}$ School of Pharmacy and Pharmaceutical Sciences, Trinity College Dublin, Dublin, Ireland.
} 
blanket? How important are transporters in pulmonary drug absorption of small molecules? What are the absorption mechanisms of proteins and peptides in the lungs? Which cells are responsible for processing slowly dissolving drug particles? Are pulmonary disease lesions better penetrated or more accessible by inhaled or systemic medications? Where are we with regard to inhaled nucleotide therapy?

These and other questions are addressed in this article. We are aiming to summarize areas where key information is still missing. We also attempt to formulate key questions that need to be answered to gain better insights into the field of inhalation biopharmaceutics.

We have decades of experience with aerosol deposition and clearance in the lungs. ${ }^{(1)}$ We also can build on abundant previous studies with delivering drugs systemically via the lungs. ${ }^{(2)}$ Often, we have described blood levels of a drug following inhalation, but rarely have we measured its persistence and location within the lungs. The field of pulmonary pharmacokinetics is underdeveloped. How rapidly do drug particles dissolve in situ and how fast and far do they spread on the surfaces of the lung?

It is clear that particles deposited in the airways often penetrate the mucus blanket without dissolution. For example, Watson and Brain ${ }^{(3)}$ reported the presence of iron oxide particulates inside airway epithelial cells following their inhalation. This shows that intact particles can move through the mucus blanket and the periciliary fluid, and may even be endocytosed by airway epithelial cells. Indeed, Gehr and colleagues ${ }^{(4)}$ have repeatedly expressed their belief that particles deposited on mucus are inevitably pushed downward by surface forces. At the same time, we know that mucociliary clearance and cough move particles deposited in airways mouthward. Expectorated particles are mixed with salivary secretions and are swallowed. The velocity and effectiveness of mucociliary transport affect the half-life of deposited drugs in the airways. The more quickly they are cleared, the less likely dissolution and absorption take place in the airways. Cough, although ineffective in normals, also moves mucus secretions mouthward in individuals with mucus hypersecretion. ${ }^{(5)}$

What about alveolar nonciliated regions of the lung? First, we need to admit that we rarely can distinguish deposition in small airways versus alveolar ducts versus alveoli. Another question is the extent to which landed particles remain at the site of their initial deposition. To what extent do they slip and slide on alveolar surfaces during breathing or do they move passively by poorly described bronchioalveolar transport mechanisms of the alveolar lining layer? In time, it is likely that they move to (and perhaps bind) the alveolar epithelial cells (primarily type I epithelial cells, because they comprise the vast majority of the alveolar surface).

We know that if particles persist-and do not dissolvethey will probably be recognized by alveolar macrophages. Strategies for evading phagocytosis such as PEGylation (PEG-polyethylene glycol) may render particles less susceptible to phagocytosis. Macrophages move on the surface of the alveoli. They also police the surface by extending pseudopods. In animal experiments, the half-life of "uncaptured" particles on the alveolar surface is of the order of several hours in rodents. The shift from extracellular to intracellular environments causes dramatic changes for drug particles. For example, the $\mathrm{pH}$ drops from a physiologic one to a more acidic $\mathrm{pH}(\sim 4.8)$ characteristic of phagolysosomes. Finally, our supposition that particles land in lung fluid and dissolve quickly is not well supported. In fact, the deep lung surface is relatively dry. The balance of forces removes water from the alveolar surface and pulls it into the blood. On most parts of the lung, particles land on lipoid molecules, for example, surfactant. Only in the corners is there a subjacent aqueous phase. We need to gather data on the rate of drug particle dissolution in situ. Perhaps if fluorescent particles were used and examined by laser scanning confocal microscopy or other associated imaging technologies (e.g., multiphoton, live cell imaging approach), we could observe the process by looking through the pleura.

Inhaled dosage forms that deliver drug aerosols onto the lung surface in a solid or semisolid form are becoming increasingly common, as these systems hold the potential to improve the duration and effectiveness of inhaled drugs and vaccines. Although we have decades of experience delivering drugs systemically via the lungs, ${ }^{(2)}$ we typically describe blood levels of a drug following its inhalation. Rarely do we measure drug/aerosol particle persistence and location within the lungs. Ensuing processes after particle deposition, such as dissolution in the lung lining fluid, lateral spreading over the lung surface, and/or penetration within the fluids, facilitate a drug's access to various locations in the respiratory tract. However, each of these processes is affected by fluid and cellular barriers and natural clearance mechanisms that operate in the lungs, which ultimately limit the availability and persistence of drugs within the lung (Fig. 1).

The complex composition and structure of the lung lining fluids lead to equally multifaceted particle-fluid interactions. Upon deposition in the lungs, drug particles first interact with the lung lining fluids, which serve as a protective barrier for the underlying epithelium. The lung lining fluid, with its limited total volume (10-30 mL in humans), serves as the mucosal fluid sink for dissolution. ${ }^{(6,7)}$ It has been shown to contain a variety of proteins and surfactants that can adsorb to particle surfaces, thereby changing their subsequent interactions, as well as catalytic enzymes for luminal metabolism. The upper respiratory tract fluid is characterized by a

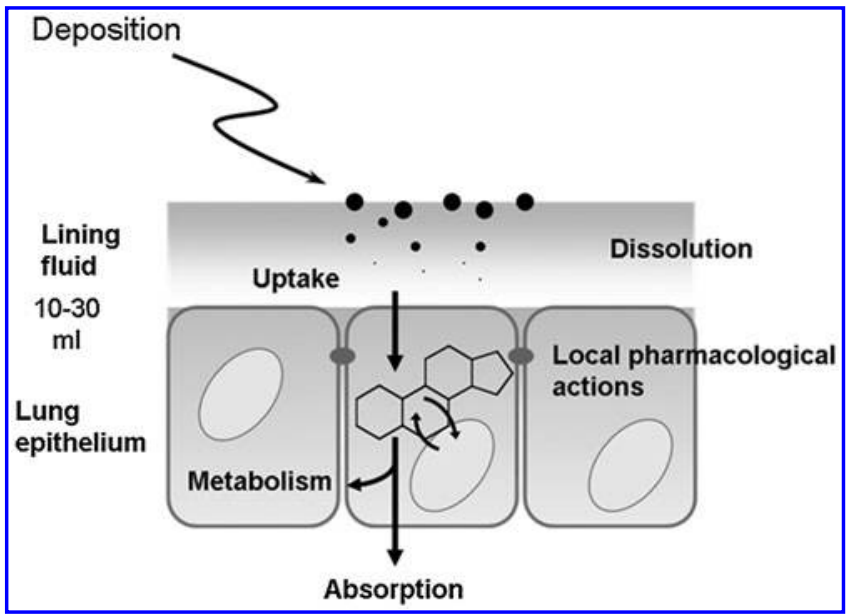

FIG. 1. General concept of aerosol drug deposition, dissolution, and absorption for local or systemic actions, modified from Edsbäcker and Johansson. ${ }^{(7)}$ 
thick $(8-15-\mu \mathrm{m})$ mucus film, which acts as a physical and chemical barrier to drug and particle diffusion. ${ }^{(8,9)}$ Drugs or particles that become trapped within the mucus matrix are rapidly cleared from the respiratory tract by mucociliary clearance. In contrast, in the lower to peripheral airways, for example, near and in the alveolar regions, the lining fluid thins to $1 \mu \mathrm{m}$ or less and has a more Newtonian consistency. It is believed, therefore, that this fluid layer provides a limited sink capacity for dissolution yet little resistance to diffusion, unless drugs and particles strongly interact with other constituents such as alveolar macrophages. The high surfactant concentration of the peripheral fluid surface, and thus the low surface tension compared to the upper airways, may promote lateral spreading of particles and drugs throughout the peripheral region and into the upper airways. This process can be augmented in any region of the lung by the addition of surfactants into the aerosol formulation. These various processes can aid drug transport or consume drug aerosols in the respiratory tract, but typically result in relatively short drug residence times and thus therapeutic actions, regardless of whether drugs act locally or systemically.

\section{Major Themes}

\section{Imaging deposited and retained particles}

Before discussing what happens to particles after they land on airway or alveolar surfaces, we need to remember that describing the anatomic distribution of deposited and retained particles is essential. Noninvasive external imaging rarely provides adequate resolution. With the use of hyperpolarized noble gases $\left({ }^{3} \mathrm{He}\right.$ and $\left.{ }^{129} \mathrm{Xe}\right)$, it will be possible to image and quantify surface area, barrier thickness, and drug concentrations in the lungs. Data are available from bronchoalveolar lavage (BAL) following inhalation of drugs. Finally, animal models are useful because more destructive procedures can be used. Lungs can be frozen or fixed and dissected. Then the amount and anatomic distribution of a drug can be measured via magnetic, radioactive, fluorescent, or elemental labels. Association of the label with the drug must be verified. With increasing time, the probability that the label is no longer reflecting the active drug increases.

\section{Particle dissolution in the lungs}

Following deposition, drug aerosols must dissolve in the lung lining fluid for subsequent cellular uptake and/or absorption. ${ }^{(7)}$ In this context, the aqueous solubility of drugs used in inhaled dosage forms is quite diverse and occasionally altered by crystal form, formulation, and aerosol generation. ${ }^{(7,10,11)}$ In addition, the lung lining fluid is limited in volume, resulting in, in certain cases, incomplete dissolution of the deposited drug aerosols. It is likely, therefore, that the kinetics of dissolution for drug aerosol particles on the lung surface could be different from those of the bulk drug materials in aqueous media. In situ dissolution could be rate-determining in lung biopharmaceutics and pharmacodynamics following inhalation. Even so, comparable pharmacokinetics were seen for readily soluble peptides (e.g., insulin and calcitonin) and antibiotics (e.g., tobramycin) following powder versus liquid aerosol inhalation in humans. ${ }^{(12-14)}$ This has suggested that aerosol dissolution on the lung surface was not kinetically critical, resulting in relatively fast absorption and disappearance from the lung. However, this may not be the case for drugs with extremely low aqueous solubility such as certain inhaled corticosteroids (ICSs), as their lung-deposited doses exceed the estimated dissolution capacity of the lung lining fluid due to its limited volume. $^{(7)}$

Fluid-limited dissolution kinetics of drug aerosols from inhaled products have been demonstrated in vitro. This depends on the drug's aqueous solubility, the aerosol mass deposited, particle size, as well as the formulation and aerosol generation. ${ }^{(10,15,16)}$ Accordingly, lung biopharmaceutics and pharmacodynamics following drug aerosol deposition can also be affected by these fluid-volume-limited dissolution kinetics, yet so far have only been shown in the in vivo animal and in vitro cell models.

In animals, a classic study by Chowhan and Amaro ${ }^{(17)}$ reported three to four times slower disappearance kinetics from the lung for 7-methylsulfinylxanthone-2-carboxylic acid, when instilled into the lung as suspension compared to solution administration. More recently, a nanosuspension by Yang et al. ${ }^{(18)}$ was successful in accelerating lung absorption of fluticasone propionate (FP), one of the least soluble ICSs, in rats, which they attributed to faster dissolution of smaller nanoparticles in the lung. In the in vitro cell model, FP aerosol deposition $(0.9 \mu \mathrm{g})$ onto the air-interface cultured Calu-3 monolayers from Flovent ${ }^{\circledR}$ HFA enabled cellular uptake of only $4.7 \%$ in $6 \mathrm{~h}$, leaving $95.3 \%$ of the cell surface, due to the limited mucosal (apical) cell lining fluid volume $(0.04 \mathrm{~mL})$ available for dissolution. ${ }^{(19)}$ As a result, its antiinflammatory response remained only at $35.7 \%$, whereas comparable $38.6 \%$ response was achieved by a much lower dose $(0.1 \mu \mathrm{g})$ of FP applied as solution, by virtue of its greater cellular uptake from the dissolved FP. ${ }^{(19)}$

In contrast to all of these findings, there has been no compelling evidence that suggests dissolution-controlled lung biopharmaceutics and pharmacodynamics in humans among the currently approved inhaled dosage forms. ${ }^{(20)}$ Meanwhile, because most inhaled drugs produce fairly fast absorption and disappearance from the lung, several attempts have been made to slow down their dissolution on the lung surface using sustained or delayed release methodologies, in order to prolong the duration of action. ${ }^{(21)}$ Nevertheless, their feasibility has been again demonstrated only in the in vitro and in vivo animal models. It remains to be seen whether such methods would work in clinical scenarios.

In conclusion, data regarding dissolution-controlled pulmonary biopharmaceutics and pharmacodynamics may exist for some drug molecules with extremely low aqueous solubility, for example, FP, fluticasone furoate, and mometasone furoate, only at the in vitro or in vivo animal levels. Moreover, it is still unclear if the manipulation of dissolution kinetics or release is feasible for drug aerosols in human lung, and it will produce more beneficial local or systemic action profiles. More quantitative in vitro and in vivo methods are essential, whereas we also need to acknowledge quantitative differences in aerosol dose equivalence to humans.

\section{Particle transport through lung lining fluids}

If particles are not immediately dissolved in the lung lining fluids after depositing, they have the ability to travel 
through the fluids and further interact with various lung structures. Several researchers have observed the presence of environmental and therapeutic aerosol particles in airway epithelial cells or the systemic circulation following their inhalation. ${ }^{(3,22-24)}$ These studies show that intact particles can move through the mucus blanket and the periciliary fluid, and may even be endocytosed by airway epithelial cells. However, particle transport through the mucosal fluids is a complex process that depends on many factors, such as particle dose, particle physicochemical properties, and the nature of the lung fluids. Therefore, a variety of strategies have been developed to enable longer residence times of particles in the respiratory fluids.

Barriers to particle transport in the respiratory tract fluids. The relatively thick, $8-10 \mu \mathrm{m}$, upper respiratory tract fluid consists of at least two layers: (1) a tightly crosslinked viscoelastic gel composed of about $95 \%$ water, $1 \%$ salt, $3-4 \%$ glycoproteins (mucins), and other macromolecules; and (2) a periciliary liquid layer beneath the gel that facilitates efficient ciliary beating. The upper gel layer acts as a physical barrier to particle transport, because pores available for transport are estimated to be less than $500 \mathrm{~nm}$ in diameter, and a chemical barrier due to attractive interactions (primarily electrostatic and hydrophobic) between the particles and mucus constituents. ${ }^{(8,25,26)}$ Particle diffusivity in mucus, therefore, is dependent on particle physicochemical properties (size, surface charge, hydrophobicity) and the available effective mucus pore size. Depending on disease state, conventional nanoparticles $(<500 \mathrm{~nm})$ are usually small enough to diffuse through low viscosity pores in the pulmonary mucosal fluids, but do not have the appropriate surface chemical properties to avoid being trapped by mucus. These trapped particles can then be rapidly cleared from the respiratory tract by mucociliary clearance. The velocity and effectiveness of mucociliary transport affect the half-life of deposited drugs and particles in the airways. For effective therapy, particle or drug diffusion must occur more quickly than they are cleared. The periciliary layer has traditionally been described as a watery, Newtonian fluid, which provides little resistance to particle transport. However, recent data suggests that this layer is comprised of tethered mucins and other macromolecules, which may provide a secondary barrier to efficient particle transport. ${ }^{(27)}$

In the alveoli, particles interact with a thin lining layer $(<0.1 \mu \mathrm{m})$ containing a variety of lipids and protein molecules. It is unlikely that this fluid layer creates a significant diffusional barrier to particle transport. Therefore, one barrier to drug availability in this region of the lung is particle phagocytosis by alveolar macrophages. For transport of drugs to the capillaries, the primary barrier is tight junctions between alveolar epithelial cells.

Strategies to improve particle transport in the upper respiratory tract. One way to penetrate pulmonary fluids is to take advantage of the surface tension of the air-fluid interface. ${ }^{(4,28)}$ Gehr and coworkers ${ }^{(4,29,30)}$ have shown that micron-sized particles of various surface chemistries that are deposited on the lung surface are partially or fully submersed in the lung lining fluid. Particles in the alveolar fluids come into direct contact with the lung epithelium due to the extremely thin fluid layer and low surface tension (close to
$0 \mathrm{dyn} / \mathrm{cm})$. However, it is unlikely that particles in the upper respiratory tract are pushed past the mucus gel layer into the periciliary layer, where clearance is less rapid.

To overcome the short residence times at mucosal sites due to clearance, particle development has largely focused on increasing association with mucus through mucoadhesive particles. This technique has shown significant promise in the gastrointestinal (GI) tract and nasal passages, and recently, improved drug bioavailability in the lungs. ${ }^{(31,32)} \mathrm{Al}-$ though mucoadhesive particles exhibit slower particle transit time from the mucosal site, this strategy is limited by the time scale for mucus renewal. In addition, concerns over abnormal changes in mucociliary clearance due to the use of mucoadhesive particles have limited this technique in pulmonary drug delivery.

Alternatively, minimizing particle mucoadhesion through modification of particle surface properties has been shown to facilitate particle diffusion through the mucosal fluids. Particles with neutral surfaces have been shown to undergo more rapid diffusion in mucus than those with charged (either positive or negative) surfaces. ${ }^{(8,33)}$ Soluble proteins adsorbed to polyethyleneimine (PEI) particle surfaces have been observed to increase in vivo gene expression in epithelial cells compared to naked PEI complexes, although there were no differences in the size the surface charge (both were negatively charged) of the particle types. ${ }^{(34)}$ The enhanced gene expression was likely due to a masking of the particle surface, limiting the binding of lung proteins and other components to the particle surface.

Coating nanoparticles with a dense covering (enough to neutralize the particle's zeta potential to $0 \pm 8 \mathrm{mV}$ ) of low molecular weight PEG (2-5 kDa) has been shown to reduce hydrophobic and electrostatic interactions with lung fluid components. ${ }^{(35)}$ Appropriate surface modification requires optimization of each formulation independently and all strategies may not be possible on every particle type. Significant questions regarding surface modification remain to be answered, including: How does disease state affect the particle size and surface requirements for transport? Why do not all particles transport in the same manner (differences in surface modification, small changes in particle size, patient characteristics, particular location that particle landed)? How do variations in patient lung structure and fluid composition affect particle transport?

Limitations of transport strategies. A variety of strategies have been developed in recent years to overcome the lung fluid barrier. However, the complex processes that ultimately dictate health outcomes still remain a black box. Therefore, the specific molecular and physical characteristics of particles that control their behavior in lung lining fluid are poorly defined. Our understanding of lung lining fluid-particle interactions is largely complicated by the difficulty in obtaining physiological lung fluids for research, especially for the noncystic fibrosis (CF) or chronic obstructive pulmonary disease (COPD) populations. There is currently a lack of good mucus mimetics to replace native mucus in these studies, as well as a general lack of fluid composition and structure profiles across different patient populations. Our knowledge of how particle properties change over time due to adsorption of various fluid and surfactant components to the particle surface and how these interactions alter delivery is primitive, especially 
compared to available data for injectable systems. Improving our knowledge base in this area would aid our ability to predict particle and drug fate in the respiratory tract and improve health outcomes in humans.

\section{The fate of macromolecules}

It has been repeatedly shown that biopharmaceuticals (e.g., peptides and proteins) can be absorbed through the airblood barrier of the deep lung into systemic circulation with measurable quantities yielding low to rather good bioavailability, although the exact mechanisms are still unclear at best. $^{(2,36)}$ Size-dependent clearance/transport of hydrophilic solutes (including proteins) across lung alveolar epithelium has been widely accepted, stressing that perhaps passive diffusion (via equivalent water filled pores whose radius may be $\sim 5-6 \mathrm{~nm}$ ) may be the predominant mechanisms for absorption of biopharmaceuticals via the deep lung into the circulation. $^{(37)}$

Present state of art. Of those biopharmaceuticals studied, insulin delivery via the deep lung into blood has received much attention, because oral delivery of insulin results in virtually no bioavailability. ${ }^{25 a}$ The exact mechanisms for the rather unexpectedly good bioavailability for insulin (and other peptides including human growth hormone) delivered via the deep lung are currently unknown, although vast areas available in the lung airspaces and the very short distance (approx $0.5 \mu \mathrm{m}$ ) between airspaces and the blood circulation in the deep lung may be the important factors for such success even if the predominant transport mechanisms may be passive diffusion.

Why we sometimes see fast as well as slow components in peptide absorption profiles (e.g., insulin) is also unclear, although differential clearance and absorption schemes in alveoli and airways are likely to contribute to overall pharmacokinetic properties. ${ }^{(38)}$ It has to be stressed that as far as peptides (and some proteins) are concerned, the respiratory epithelial tract may not be construed as a relatively weak enzymatic barrier, because various studies in vitro and in vivo indicate that many types of peptidases/proteases are lurking in the airspaces and the lining cells of the respiratory epithelia. ${ }^{(39)}$ In this regard, the usage of antiproteases and peptidase inhibitors along with biopharmaceuticals (especially peptide and protein drugs) may be indicated for successful formulation and efficacious pulmonary drug delivery.

It can be also noted that several cognate receptors for various serum proteins (e.g., albumin, transferrin, immunoglobulin G, and polymeric immunoglobulin A) are identified and studied in detail for their roles in absorption/secretion of various proteins across the alveolar epithelial barrier. ${ }^{(37)}$ Other more general receptors (e.g., more promiscuous megalin and other scavenger type receptors) may also play some role(s) in transport of protein drugs. By extension of this concept, other biopharmaceuticals may be able to be absorbed (albeit intracellular degradation at lysosomes may be a major hurdle to overcome) via these latter receptors. No systematic investigation pertaining to such transport has been reported to date.

What critical information is missing?. Certainly, more in depth information on specific receptors/vesicular pathways for biopharmaceuticals would be helpful to deduce whether such receptors play any roles in mediating transport of specific biopharmaceuticals across alveolar epithelium. Also needed would be critical evaluation of transport data obtained using a rodent alveolar epithelial model versus human alveolar epithelial model, because some differences appear to be more than apparent in absorption level/profile of several biopharmaceuticals across the popular rodent model versus the human alveolar epithelial model. ${ }^{(40)}$ The contribution of nasal/tracheobronchial/alveolar epithelium in pulmonary absorption of a given biopharmaceutical would be important in determining the role of various respiratory epithelial barriers in overall absorption of the biopharmaceutical via the pulmonary route into the systemic circulation. Although a proton-dependent peptide transporter (most likely PEPT2) and several amino acid transporters have been reported to be expressed in various respiratory epithelia, we currently do not have any evidence as to whether biopharmaceutical absorption via these transporters could occur. Finally, localization and activity of peptidases in various regions of the lung (e.g., trachea vs. bronchus vs. bronchiole vs. alveolus) have to be investigated to better understand if protective measures such as PEGylation or peptidase inhibitors are efficacious.

The role of macrophages in macromolecule disposition. Data have indicated that alveolar macrophages and respiratory tract dendritic cells play a significant role in the local fate of macromolecules. Different microscopy techniques, including optical, confocal, and electron microscopy, have shown that macromolecules delivered to the animal lung are internalized by alveolar macrophages. ${ }^{(41)}$ Studied animal species were not limited to small rodents but also included large animal species such as sheep and the monkey. Yet microscopy provides only a qualitative assessment of alveolar macrophage uptake with no quantification of its impact on systemic absorption.

Using a rat model depleted in alveolar macrophages in vivo, Lombry et al. ${ }^{(42)}$ provided the quantitative demonstration that macromolecule uptake by alveolar macrophages was a significant clearance pathway for inhaled proteins.

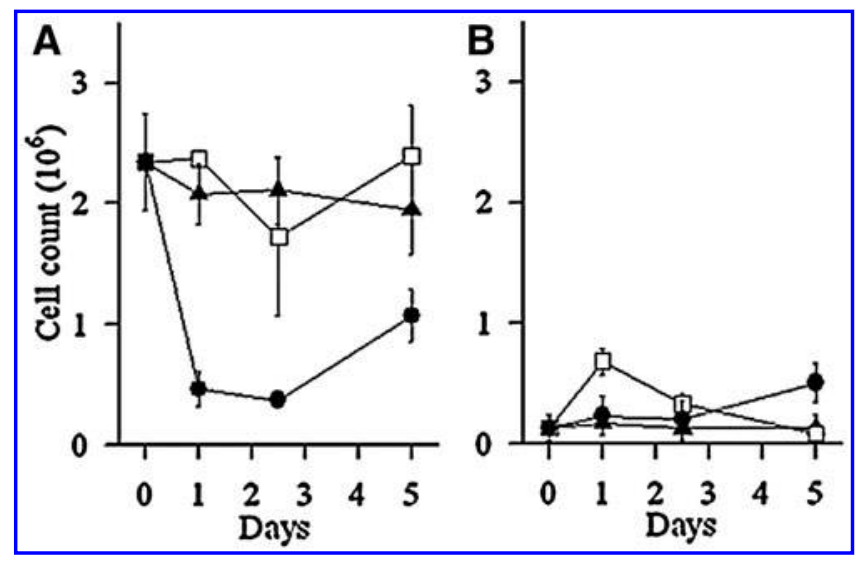

FIG. 2. Impact of intratracheal instillation of clodronate liposomes on the number of alveolar macrophages (A) and neutrophils (B) in bronchoalveolar lavage in rats. From Lombry et al. ${ }^{(42)}$ 


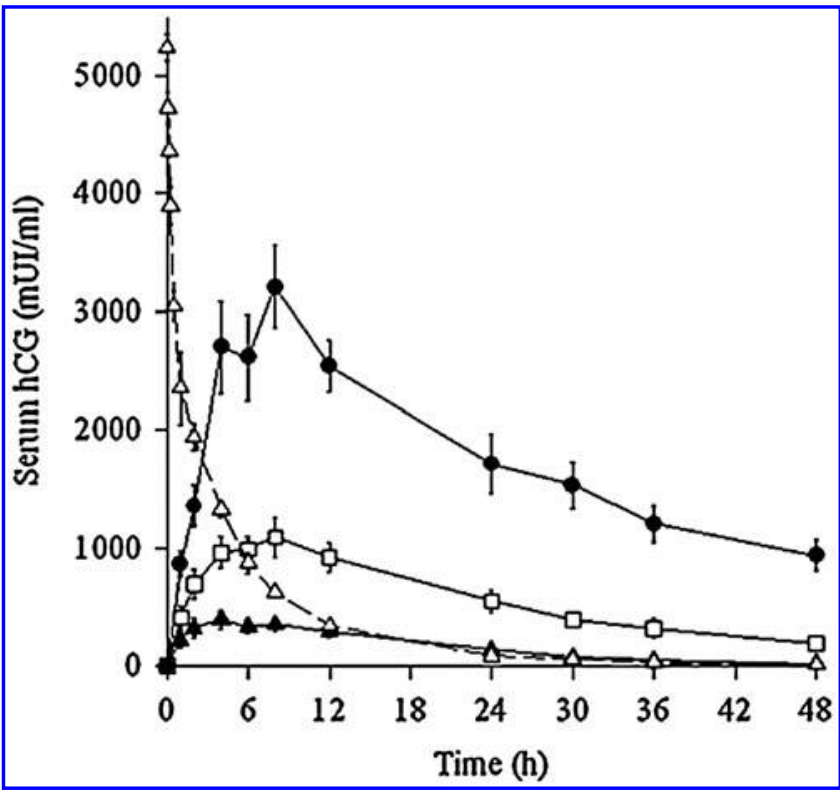

FIG. 3. Pharmacokinetics of pulmonary human chorionic gonadotropin in alveolar macrophage-depleted and control rats. Rats received a hormone dose of $100 \mu \mathrm{g}$ by intratracheal instillation 1 day after clodronate $(\bullet)$ or PBS $(\square)$ liposome administration or no treatment $(\boldsymbol{\Lambda})$. From Lombry et al. ${ }^{(42)}$

Alveolar macrophages were depleted by locally delivering liposome-encapsulated clodronate, which caused apoptosis of alveolar macrophages. ${ }^{(43,44)}$ In those experiments, 1 day after liposome treatment, rats presented a fivefold decrease in alveolar macrophage count in bronchoalveolar lavage (Fig. 2A). Local administration of liposomes was not associated with significant inflammation (Fig. 2B). ${ }^{(42)}$

Figure 3 shows an example of pharmacokinetic data obtained in the alveolar macrophage-depleted animal model and for comparison in control rats. A substantial rise in serum human chorionic gonadotropin levels resulted from the depletion of alveolar macrophages. The pulmonary bioavailability of the hormone relative to i.v. injection increased from $4 \%$ in untreated rats to $18 \%$ in empty liposomes-treated rats, to $60 \%$ in clodronate liposomes-treated rats. ${ }^{(42)}$

Table 1 describes the enhancement in bioavailability of other proteins that followed alveolar macrophage depletion. Alveolar macrophages significantly competed with the transport of IgG from the airways into the bloodstream as well, whereas they had no impact on smaller proteins such as insulin and human growth hormone. The dependence of alveolar macrophage clearance on macromolecular weight might be explained quite simply by the relationship between the residence time in the airways and molecular weight. The time it takes proteins to peak in blood after pulmonary delivery is molecular weight-dependent; the larger the size, the slower the absorption. Small proteins such as insulin are quickly absorbed through the epithelium and degradation by alveolar macrophages may be minimal because of their short residence time within the alveoli. The longer the time of residence of the macromolecule within the airspaces, the longer its contact with, and uptake by, alveolar macrophages. $^{(41)}$

Parameters other than the molecular weight can affect the rate of protein transport across the epithelium or the rate of alveolar macrophage uptake. Receptor-mediated transport across the alveolar epithelium leads to increased protein absorption rates, ${ }^{(45)}$ and thereby to shorter residence time within the alveolar spaces. Receptor-mediated endocytosis by alveolar macrophages (e.g., endocytosis via the mannose or $F_{C}$ receptor $)^{(46,47)}$ is a faster process than fluid-phase or adsorptive endocytosis, and this mode of uptake is expected to increase protein clearance by alveolar macrophages. A global cationic charge on the protein promotes adsorptive endocytosis (Table 1). ${ }^{(41)}$

However, the significance of alveolar macrophage uptake remains to be demonstrated in humans. Moreover, methods to avoid alveolar macrophage uptake of macromolecules need to be developed, as they could increase systemic bioavailabilities following pulmonary delivery. Alveolar macrophage depletion using liposomal clodronate is not feasible in humans because the absence of alveolar macrophages would predispose individuals to infections and disrupt pulmonary physiology. ${ }^{(48)}$ Therefore, the prevention of protein uptake by alveolar macrophages represents a particularly challenging task because the methods should not compromise macrophage function. ${ }^{(41)}$

Antigenic proteins have been shown to be taken up by respiratory tract dendritic cells and alveolar macrophages within hours of administration. ${ }^{(49,50)}$ After antigen uptake, respiratory tract dendritic cells migrate to lung draining lymph nodes for presentation of processed antigen to $\mathrm{T}$ cells (Fig. 4). Immune responses are moderate, unless ligands for pattern recognition receptors are codelivered. ${ }^{(51)}$

Alveolar macrophages do not migrate to regional lymph nodes and do not present antigen effectively to T cells (Fig. 5). Alveolar macrophages are ineffective in antigen presentation because they fail to express B7 antigens, which ligate CD28 on $\mathrm{T}$ cells and provide a costimulatory signal required for activation of T cells. ${ }^{(52)}$

Table 1. Physicochemical Properties of Proteins Possibly Affecting AM Uptake

\begin{tabular}{lccccc}
\hline Molecule & $M W(k D a)$ & $p I$ & Glycosylation & $\begin{array}{c}\text { Specific } \\
\text { receptor on } \\
\text { AM/epithelium }\end{array}$ & $\begin{array}{c}\text { Enhancement } \\
\text { factor in bioavailability } \\
\text { due to AM depletion }\end{array}$ \\
\hline Insulin & 6 & 5.3 & - & - & 0.7 \\
hGH & 22 & 5.2 & - & - & 1.1 \\
hCG & 39.5 & 3.3 & + & - & 3.4 \\
IgG & 150 & $7-8$ & + & + & 2.3 \\
\hline
\end{tabular}

hGH, human growth hormone; hCG, human chorionic gonadotropin; AM, alveolar macrophages. 


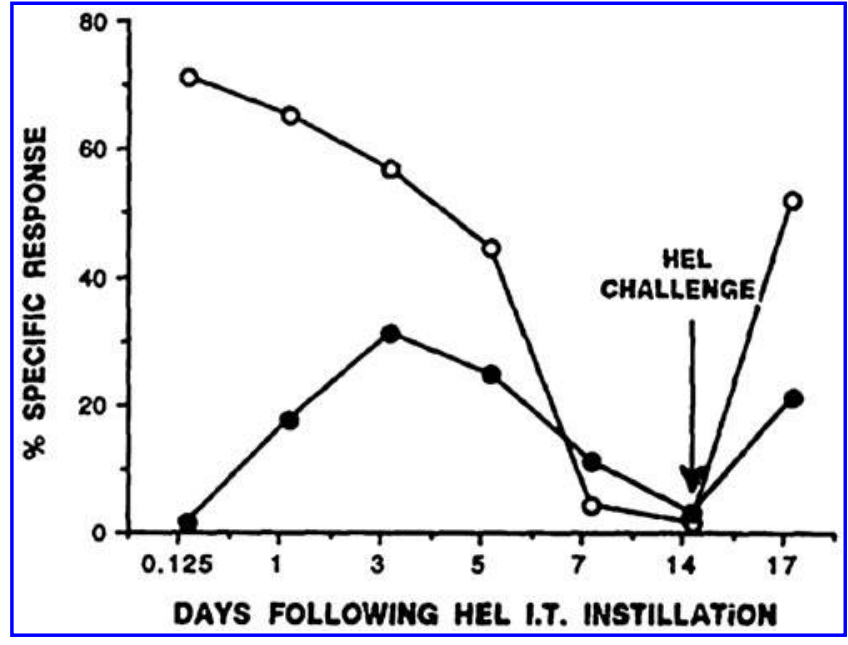

FIG. 4. The kinetics of dendritic cell-associated antigen presenting cell activities after an airway challenge with henegg lysozyme in rats. Dendritic cells from the lung $(\bigcirc)$ showed peak antigen presenting cell activity at $3 \mathrm{~h}$, which subsequently decreased gradually to day 7. Antigen-presenting cell activity in the draining hilar lymph nodes (•) peaked at day 3 and was detectable until day 14 . When rats received a second challenge with hen-egg lysozyme intratracheally, specific dendritic cell-associated antigen presenting cell responses were again stimulated in lung and lymph nodes. From Xia et al. ${ }^{(135)}$

Alveolar macrophage uptake of antigens shields local tissues from development of specific immune responses. ${ }^{(51)}$ In addition, alveolar macrophages present immunosuppressive activities, that is, they actively downregulate the antigenpresenting functions of dendritic cells (Fig. 6). ${ }^{\text {(50,51,53) }}$

To avoid collateral damage to type I and type II cells in response to harmless antigens, alveolar macrophages are kept in a quiescent state, producing little inflammatory cytokines. ${ }^{(54)}$ Alveolar macrophages adhere closely to alveolar epithelial cells, and this in turn induces the expression of the integrin $\alpha \mathrm{v} \beta 6$ on alveolar epithelial cells. This integrin binds and activates tumor growth factor (TGF)- $\beta$ in the vicinity of the macrophage and binding of activated TGF- $\beta$ to its re-

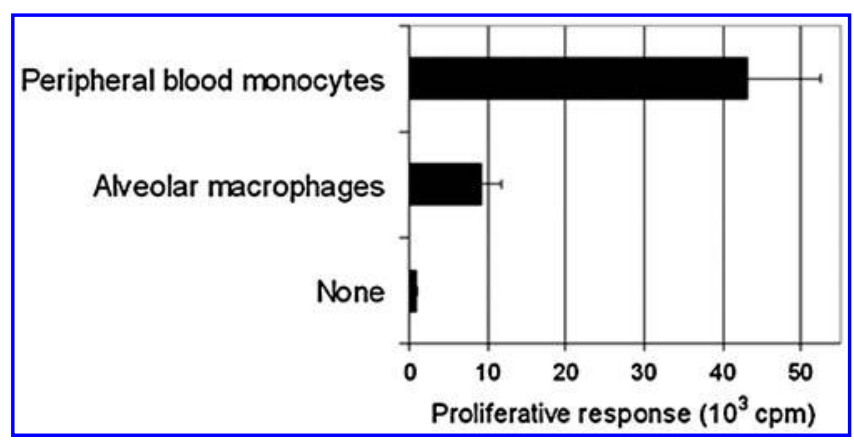

FIG. 5. Antigen-presenting cell functions of alveolar macrophages and peripheral blood monocytes. Purified $\mathrm{CD}^{+} \mathrm{T}$ cells were cultured with tetanus toxoid and the indicated antigen-presenting cell type. The proliferative response was determined by the incorporation of ${ }^{3} \mathrm{H}$-thymidine over the last $18 \mathrm{~h}$ of a 6-day culture. Adapted from Chelen et al. ${ }^{(52)}$

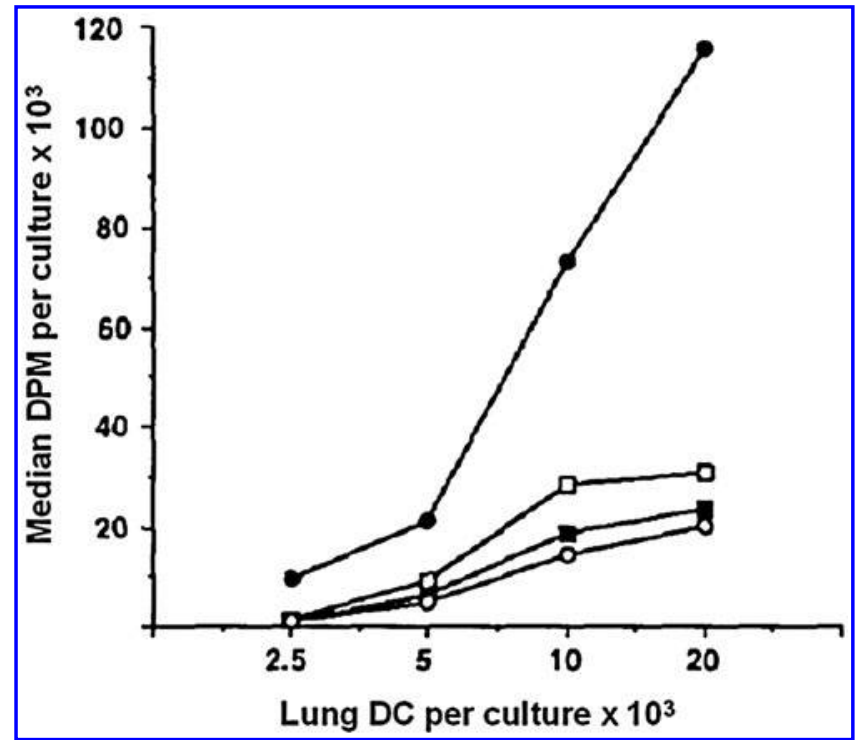

FIG. 6. Effect of prior depletion of alveolar macrophages on antigen presentation by lung dendritic cells. Lung dendritic cells from groups of control or treated rats were titrated into cultures of lymph node T cells and resulting DNA synthesis determined as incorporation of ${ }^{3} \mathrm{H}$-thymidine at the $120-\mathrm{h}$ time point. Lung dendritic cell pools were from untouched controls ( $\boldsymbol{\square})$, and animals intratracheally inoculated $48 \mathrm{~h}$ previously with either PBS $(\bigcirc)$ or liposomes containing PBS $(\square)$ or clodronate $(\bullet)$. From Holt et al. ${ }^{(53)}$

ceptors on macrophages suppresses cytokine production by macrophages.

It is well known that dendritic cells in the lung trigger immune responses but it remains to be demonstrated whether systemic absorption of part of the antigen dose also plays a role. To enhance immune responses for vaccination purposes, the uptake of antigen by lung dendritic cells should be optimized, as is done for other routes of vaccine administration. ${ }^{(55)}$

\section{The role of drug transporters in pulmonary drug disposition}

Carrier transporters can impact upon the absorption and disposition of low-molecular weight drugs leading to alterations in pharmacodynamics and potentially leading to organ toxicity. The study of drug transporters has progressed particularly in intestinal, renal, and blood-brain barriers. The main groups of drug transporters so far investigated include: the ATP-dependent Binding Cassette (ABC) transporters including P-glycoprotein (P-gp), Multidrug Resistance Proteins (MRPs), and Breast Cancer Resistance Protein (BCRP); the family of organic cation transporters (OCTs) and organic cation/carnitine transporters (OCTNs); the family members of the organic anion transporters (OATs) and organic anion transporting polypeptides (OATPs); and the peptide transporters (PEPT1/PEPT2).

The rate and extent of epithelial permeation of drugs in the lung depends upon the dose and deposition site of drug within the lung, the passive permeability of the epithelial barrier to drug, any parallel and sequential drug clearance mechanisms and the characteristics of any active drug 
transporters expressed in lung epithelium. Given the wide range of different cell types in the lung, the varying nature of the epithelium along the respiratory tract and the quite distinct deposition patterns that can result from aerosol inhalation of drug, it is the spatial pattern of pulmonary drug transporter expression that is significant. However, the spatial expression of drug transporter proteins is generally poorly defined. ${ }^{(56)}$ Further, the functional significance of transporters within the intact lung has been explored in only a limited manner.

The commentary that follows will concentrate on appraising evidence gained from intact lung tissue (primarily human) on the spatial expression of drug transporters, particularly in respect to the lung epithelial cells. Further, where applicable, some assessment is provided of the intact organ studies addressing transporter functionality. The reader is also directed to the reviews of Bosquillon, ${ }^{(57)}$ van der Deen and colleagues, ${ }^{(58)}$ and Gumbleton and colleagues. ${ }^{(59)}$

P-gp. P-gp substrates comprise a broad range of structurally diverse molecules. ${ }^{(60-62)} \mathrm{P}$-gp is encoded in humans by the MDR1 gene and in rodents by mdrla and mdr1b genes. In rodent lung it is the mdr1b mRNA that predominates. ${ }^{(63,64)}$

A number of studies have described the localization of $\mathrm{P}$ gp in intact human lung ${ }^{(64,65-69)}$ with P-gp expression appearing well defined at the luminal surface of bronchi/ bronchiolar epithelium. Some evidence exists for P-gp expression at the luminal (blood interface) surface of bronchial capillaries ${ }^{(65,66)}$ and for P-gp expression in alveolar macrophages. ${ }^{(67,68)}$ Contrasting reports highlight both of the lack of P-gp signal in alveolar epithelium ${ }^{(65,67)}$ and the presence of P-gp-associated signal along the entire surface of alveolar epithelium, ${ }^{(64)}$ the latter finding corroborated by P-gp protein expression and functionality in primary rat ${ }^{(64)}$ and human $^{(69)}$ alveolar epithelial cells isolated from the respective lung tissue. There is a need to confirm using electron microscopy techniques, the discrepant findings for P-gp in alveolar epithelium and to explore the expression of P-gp in pulmonary vascular beds.

Even for P-gp, only a few functional investigations within intact lung tissue have directly attempted to address its impact upon the extent and rate of pulmonary solute absorption. Losarten, a P-gp substrate, shows a high extent of absorption following administration into the airways of both an in vivo fully intact animal ${ }^{(70)}$ and of an isolated perfused rat lung (IPRL) model. ${ }^{(71)}$ Manford et al. ${ }^{(72)}$ reported no effect of mdr1a deletion upon the rate or extent of pulmonary absorption of the P-gp substrate digoxin from the airways of CF-1 mice, which display a mdr1a $(-/-)$ but $\operatorname{mdr} 1 b(+/+)$ phenotype. Using an IPRL model, coadministration into the airways of the P-gp inhibitor GF120918 $(2 \mu \mathrm{M})$ has been shown not to affect the pulmonary absorption profile of digoxin. ${ }^{(73)}$ In contrast in another IPRL model, the presence of GF120918, in both the circulating perfusate $(0.5 \mu \mathrm{M})$ and coinstilled into the airways $(1 \mu \mathrm{M})$, resulted in significant enhancement in the rate and extent of pulmonary absorption for the P-gp substrate rhodamine-123 (Rh123); ${ }^{(74)}$ an effect not mediated through a generalized enhancement in the lung permeability. Additional functional investigations on the role of P-gp in the intact lung are needed, including studies addressing not simply the extent of systemic absorption but the impact of P-gp upon intraluminal drug recycling kinetics. These may be best addressed using knock-out mice or at least a combination of various P-gp substrates and inhibitors. It should not be forgotten that a drug's physiochemical properties driving passive transport across the cell membrane serve to reduce membrane residence time and opportunity for P-gp binding.

MRPs and BCRP. The MRPs are responsible for the cellular efflux of a wide range of amphipathic anions. ${ }^{(75,76)}$ MRP1 is the most studied member of the subfamily in terms of drug transport. MRP1 predominantly localizes to the basolateral membranes in epithelial cells. However, in normal human lung MRP1 has been shown to variously display strong cytoplasmic staining toward the apical zone of bronchial and bronchiolar epithelial cells ${ }^{(77)}$ or toward the basolateral zone in bronchial and bronchiolar epithelial cells ${ }^{(68)}$ and the basolateral zone in ciliated epithelial and mucus cells from primary and lobar bronchi. ${ }^{(78)}$ Alveolar macrophages appear to express MRP1 ${ }^{(68,77)}$ but alveolar pneumocytes have been reported to lack MRP1. ${ }^{(77)}$

$\mathrm{BCRP}$ has a broad range of substrates extending beyond anticancer agents to include antivirals, HMG-CoA reductase inhibitors, antibiotics, and calcium-channel blockers. ${ }^{(79)}$ Low levels of BCRP have been reported in bronchial epithelial cells and in small endothelial capillaries of the lung. ${ }^{(68)}$ BCRP has also been reported in alveolar pneumocytes from normal human lung. ${ }^{(80)}$

Evidence for MRPs and BCRP transporter functionality within the intact lung is lacking.

OCT/OCTN. The polyspecific organic cation transporters, OCT1, 2, and 3, translocate a range of organic cations of differing structures in a bidirectional manner. ${ }^{(81)}$ The two carnitine/cation transporters OCTN1/2 are characterized by their ability to transport the zwitterionic L-carnitine as well as organic cations.

Evidence for OCT and OCTN transporter functionality within the intact lung is lacking. However, some information on the spatial pattern of protein expression in intact human lung is available. The OCT1, OCT2, and OCT3 proteins have been reported ${ }^{(82)}$ to all display luminal membrane expression in bronchial ciliated epithelial cells. Both OCTN1 and OCTN2 have also been shown ${ }^{(83)}$ to be expressed in the apical portion of airway epithelial cells, with OCTN2 also showing relatively strong expression at the surface of alveolar type I epithelium.

A number of respiratory drugs are organic cations and the functioning of OCTs and OCTNs may have a significant impact on the disposition of lung-administered compounds. For example, in vitro studies have shown active uptake of ipratropium by human bronchial epithelial cells via an organic cation uptake mechanism, most likely represented by OCTN. ${ }^{(84)}$ Similar finding have previously also been reported for albuterol (salbutamol) and formoterol. ${ }^{(83,85)}$

OAT/OATP. The OATs comprise six isoforms with substrates that include a chemically heterogeneous range of weak acids bearing a net negative charge at physiological pH. ${ }^{(86)}$ In 2006, Bleasby et al. ${ }^{(87)}$ reported upon a microarray analysis of drug transporter genes in whole tissues. For the 
lung, Bleasby et al. reported an absence of OAT transporters, other than OAT2, a finding in general agreement with that of others using RT-PCR or Northern blot techniques [see ${ }^{(57)}$ ].

The OATPs mediate the bidirectional cellular transport of a wide range of molecules and are capable of carrying cationic, neutral, zwitterionic, as well as anionic compounds [see ${ }^{(88)}$ ]. In human lung tissue the findings of Bleasby et al. ${ }^{(87)}$ were consistent with those of Tamai et al. ${ }^{(89)}$ in that the only OATP mRNA transcripts found in lung at any significant level were OATP4A1, OATP3A1, OATP2B1, and OATP2A1.

No evidence for the spatial expression or functionality within the intact lung exists for OATs and OATPs proteins.

PEPT1/PEPT2. PEPT1 and PEPT2 are proton-oligopeptide cotransporters. They are di- and tripeptide transporters with a broad substrate capacity such that many small peptide-like drugs, as well as nonpeptidic drugs, can also serve as substrates.

Using RT-PCR or Northern analyses, a number of researchers have documented PEPT2 mRNA in the lung tissue of rodents or rabbits, while PEPT1 is essentially absent or extremely low. In human lung tissue, Bleasby et al. ${ }^{(87)}$ reported transcript levels for PEPT1 to be low to absent, whereas that for PEPT2 was high. In the human lung, PEPT2 staining has been reported ${ }^{(90)}$ in tracheal, bronchial, and bronchiolar epithelial cells, with a prominent expression at the apical cell borders. Cytoplasmic staining for PEPT2 was observed within type II pneumocytes, although staining for PEPT2 could not be detected in alveolar macrophages or type I pneumocytes.

Summary. Some key aims in the study of pulmonary drug transporters include determining the presence and spatial pattern of expression of drug transporters within normal human lung and the lungs of various genera (e.g., rats and mice) that are used as models for pulmonary or systemic pharmacokinetic investigations. Further, the spatial localization of transporter protein needs to be related to functional impact upon pulmonary drug absorption and disposition. This latter aim is hindered by functional redundancy in transporter activity, the broad substrate specificity of transporters, and the lack of truly specific inhibitors-coupled with the need to achieve effective inhibitory local concentrations within model systems displaying an intact lung architecture, that is, in vivo or ex vivo isolated perfused organ models. Exploitation of knock-out mice may prove fruitful together with application of appropriate techniques for small animal pulmonary delivery; the deposition pattern of aerosol in the lung may impact upon the significance of a transporter upon drug absorption and disposition.

Pulmonary drug transporters may actively remove drugs from the systemic circulation resulting in lung accumulation, leading to potential lung toxicity and altered systemic pharmacodynamics. As such, the functionality of pulmonary drug transporters may have broader implications for drugs administered by nonpulmonary routes such as the oral dosing. There is also a need to understand from a pulmonary perspective the effect of disease upon drug transporter function and the potential for drug-drug interactions and contributions to interindividual variation.

\section{The importance of pathophysiology on drug absorption from and within the lung}

"The disease is in the pulmonary artery wall, will an inhaled drug penetrate there?-They can hardly breathe and you want them to inhale a drug?-Isn't the best way to access the tumor from the blood side?-Their lungs are full of fluid, an aerosol will not work!" Biology is always the most difficult part about drug delivery, and there are many questions about how to best treat lung diseases with therapeutic molecules.

Some general concepts about pulmonary drug absorption from the airways are known. Many studies show that most small molecules have very high systemic bioavailabilities following deposition in the lungs and their rates of absorption, unless the small molecule is very insoluble, are fast (half times of seconds to tens of minutes). The picture with macromolecules is more complex. As a class they are absorbed more slowly and have bioavailabilities and pharmacokinetics that are determined by susceptibility to enzyme breakdown and regional deposition [see earlier sections in this article, and for a recent review see $\left.{ }^{(2)}\right]$. However, remarkably little is known about precisely how and where drugs are absorbed at the cellular level (either from the blood or airway side) and how long they reside in the different cells and regions of the lungs in health and disease. This badly needed knowledge could help speed the development of therapies for a group of deadly lung diseases including pneumonia; adult respiratory distress syndrome (ARDS), where the lungs fill with fluid; the nonfluid lesions of idiopathic pulmonary fibrosis (IPF); primary pulmonary hypertension ( $\mathrm{PAH})$; lung cancer; aspergillosis; other infections where microbes create barrier matrices (biofilms and granulomas); and lesions such as in COPD, tuberculosis, and cystic fibrosis.

Present state of the art. Inhalation technology today [see other reviews in this issue and ${ }^{(91)}$ ] is capable of reliable delivery of aerosol drugs to even the sickest patients (in or out of intensive care) and those with the weakest breathing. However, aerosol particles will not necessarily distribute into diseased areas of the lungs, and there is abundant evidence that disease and smoking modifies the absorption pharmacokinetics of drugs delivered to the lungs [see, e.g., ${ }^{(92)}$ ]. Asthma, emphysema, fibrosis, pneumonia, CF, and other conditions clearly affect the bioavailability of drugs deposited in the lungs. This occurs at multiple stages. First, the pattern of deposition of inhaled aerosols is dramatically altered by disease. This reflects alteration in the distribution of ventilation as well as altered fluid mechanics, such as increased Reynolds numbers caused by bronchoconstriction or airway obstruction. We also know that portions of the lung that are not ventilated receive no aerosol. Both animal models as well as human studies show us that patterns of particle deposition are increasingly nonuniform as pulmonary disease becomes more severe. Godleski and colleagues ${ }^{(93-97)}$ published a series of articles on the patterns of deposition in normal lungs and models of disease in animals. These studies are often overlooked when people talk about delivery of drugs by inhalation to patients with chronic lung diseases. However, they show clearly that the aerosols go preferentially to the more normal areas of the lung, especially in fibrosis. With airway disease, the aerosols tend to deposit 
primarily in the obstructed airway "hot spots" and to not penetrate more deeply, which may be desirable for the patient. Aerosols will deposit in and treat those parts of the lungs that are still ventilated, and presumably some drug will diffuse into obstructed areas.

We also know that particle clearance and we suspect drug absorption are related to anatomic site. As the site of particle deposition is changed, resulting absorption characteristics do also change. However, in at least one study, ${ }^{98}$ inhaled small molecule hydrophilic solutes were rapidly and extensively absorbed independent of the intrapulmonary aerosol deposition pattern, based on ${ }^{99}$ mTcDTPA. Finally, even at the same site, disease may alter absorption characteristics. Emphysema, characterized by loss of surface area and airway obstruction, will reduce absorption. Fibrosis and associated increases of the air-blood barrier may reduce diffusion of drugs across the air-blood barrier. Inflammatory changes and increased amounts of neutrophil elastase, such as is seen in cystic fibrosis, may create a more hostile environment for proteins.

Today, despite the above-mentioned concerns of poor aerosol penetration in some pulmonary disease states, treatment of most lung diseases by inhaled medications is favored over systemic therapies (oral or intravenous). The rationale is that inhalation yields higher lung and lower systemic drug concentrations, with an overall benefit of lower total body dose and lower potential for adverse events. This rationale is well proven in asthma and cystic fibrosis, and should apply to other lung diseases and infections. However, the "inhalation is better" rule may not always hold, such as the case where the inhaled medication is absorbed very fast or the diseased area of the lung is inaccessible to the inhaled drug. Treatment of lung disease from both the blood and airway side may also make sense, for example, in ventilator associated tracheobronchitis. ${ }^{(99)}$

It is well known that different conditions affect absorption of inhaled medicines. For example, insulin absorption is increased during exercise and among smokers, unaffected by upper respiratory tract infections, and decreased in asthmatics and increased in patients with COPD. ${ }^{(92,100)}$ Again, though, this information is of the "black box" kind-we measure what goes in and out, without knowing exactly where and how. Some of the cellular and tissue barrier properties of different parts of normal lungs are generally known [for a review, see ${ }^{(36)}$ ]. However, the permeability and accessibility of therapeutic drugs to the different lesions of many pulmonary diseases remains largely unknown.

Solid lung disease lesions and fluid-filled lung. The treatment of lung disease with inhaled medicines has a sound scientific rationale-targeted delivery, with high local concentrations, reduced systemic side effects, and reduced overall body dose. The approach has been widely accepted for the treatment of asthma, cystic fibrosis, and to some extend, COPD. Although many factors such as smoking, exercise, airway restriction, and the numerous lung diseases themselves can increase or decrease the absorption of inhaled medicines, the over riding rationale for inhaled therapies for lung diseases has held up. For systemic applications of inhaled medicines the scientific rationales, that is, faster action, noninvasive delivery of proteins, avoidance of first-pass metabolism, are less compelling. Here the lungs are presumably healthy but if not, then pathophysiology is thought to be a confounding factor that must be taken into account by drug developers. Fortunately, the enormous surface area of the lungs usually enables inhaled drugs to be adequately absorbed regardless of underlying lung diseases. However, there are many questions about exactly how, where, and how much drug is absorbed in diseased lungs and improvements in our understanding are urgently needed to address a wide spectrum of deadly lung diseases.

The penetration of drugs into solid pulmonary lesions and fluid-filled lungs to elicit therapeutic effect is a challenging nascent field with potential for great new discoveries. The following are some key questions, whose answers could significantly facilitate drug treatment of pulmonary diseases.

- How do drugs penetrate, and what affects residence time in diseased lung lesions?

- What is the structure and local microenvironment of solid pulmonary disease lesions $(\mathrm{pH}$, density, oxygen concentration, osmotic pressure, matrix pore sizes, etc.)?

- What receptors could enable specific targeting to pulmonary disease tissue?

- How can inhaled medications facilitate drainage of fluid filled lungs?

- Is systemic, local, or both routes of drug delivery the best way to access diseased lungs?

The following are five deadly pulmonary disease classes with markedly different structural and cellular manifestations, plus wide variability within any individual class. We know very few answers to the above questions in these diseases. One could easily base a brilliant career on addressing these questions.

IPF and other pulmonary fibroses. IPF, which has a prognosis as bad as lung cancer, and other fibrotic lung diseases are challenging for drug delivery because of the heterogeneity of the lesions and the decrease in vascular density and increase in sclerotic condition of remaining vessels as fibrotic score increases. ${ }^{(101)}$ In general, in IPF, fibroblast foci "march" from the periphery to the center of the lungs, but atypical patterns can also be found. Regardless of the specific pattern of lesions, aerosols should enable the leading edge of the fibrotic progression at the air tissue interface to be targeted with inhaled drugs. ${ }^{(102)}$ With inhaled macromolecules or sustained release small molecules (e.g., entrapped within liposomes or polymers), one could potentially have a depot of drug that provides continuous exposure to the fibrotic lesions.

$\mathrm{PAH}$. The advanced vascular lesions of the arterial walls in PAH, characterized by hyperproliferation of the adventitia, intimal, and smooth muscle cells and formation of plexiform lesions, ${ }^{(103,104)}$ have been likened to a form of nonmetastasizing cancer in that both cancer and PAH show actively proliferating cells without apoptosis. ${ }^{(105)}$ The authors claim that the concept of PAH as a "quasimalignant" state provides a new framework for antiproliferative and antiangiogenic therapy. This may be the case, but the question remains as to how to best target drugs to these enlarged sclerotic vessels that are enmeshed in the tissue of the lungs. The administration of vasodilators, both from the blood side and from aerosols, has been shown to be weakly efficacious in PAH. The first inhaled product, iloprost, was so rapidly 
metabolized and cleared that it needed to be inhaled seven to eight times a day (inhaled sustained release forms are in development). The results do suggest that at least in the case of the small molecule prostacyclin analog, iloprost, that inhalation can provide some beneficial effect. ${ }^{(106)}$ But it is unclear how the drug penetrates the lung tissue and exerts its effects. High molecular weight aerosol drug particles could serve as sustained release vehicles to treat PAH locally, and this is in fact where the field is going.

Lung cancers. Pulmonary tumors take many forms and develop from a variety of precursor cells. ${ }^{(107)}$ Treating lung cancer by inhalation has been shown to be feasible in animals, ${ }^{(108)}$ but the work has not yet led to significant drug development for humans, primarily because once lung cancer is detected in humans, it is thought to have already spread to other parts of the body, so drug treatment is given systemically. Nevertheless, the rationale for inhaled therapies to treat lung cancer or precancerous conditions is sound, that is, targeted therapy with reduced systemic side effects. Some cancers that metastasize to the lungs could also potentially be more effectively treated by inhalation than by systemic treatments. Chemoprevention of lung cancer by drug treatment has been proposed for some time but has not progressed because of the lack of good drug candidates and the long duration and large size of trials needed to show efficacy.

Cancer treatment in general has struggled for more than 100 years to design the prized "magic bullet" first proposed by Paul Ehrlich, ${ }^{(109)}$ whereby a drug lethal to tumors and cancer cells is selectively delivered to the tumor or cancer cell but avoids healthy tissues and cells. The reasons for lack of success of almost all efforts in this field are well known and include poor tumor targeting, lack of tumor selectivity, development of tumor resistance, poor residence time of drugs, drug metabolism, and genetic variation. Aerosol delivery directly to cancerous or precancerous tissue in the lungs enables a major feature of the "magic bullet" - targeted delivery with greatly reduced systemic side effects.

A feature of solid tumors that has stimulated significant drug delivery research is called the "enhanced permeability and retention effect of intravenous (i.v.) macromolecular drugs in solid tumors" (the EPR effect), whereby macromolecular drugs accumulate (are trapped) due to the tumor's leaky vascular system and lack of lymphatic drainage. The EPR effect was first described in 1986, and has since spawned the development of numerous high molecular weight tumor targeting constructs. ${ }^{(110)}$ The lungs natural very slow absorption of high molecular weight macromolecules along with aerosol delivery offers a natural retention effect for antitumor constructs in the lungs. This retention, along with the addition of targeting moieties to these constructs, could achieve the magic bullet. One technique to study the pharmacokinetics of drugs in tumors that could be applied to lung cancers is the microdialysis technique. ${ }^{(111)}$

Microbial biofilms, granulomas, tubercles, and aspergillomas. Many deadly microbial infections in the lungs induce the formation of special self-protecting colonies and structures. In tuberculosis, the structures are known as granulomas or tubercles and consist of a mixture of immune cells and bacteria and may carry dormant microbes. In aspergil- losis, the structures are called aspergillomas. In CF, diffuse panbronchiolitis and bronchiectasia are known as biofilms. ${ }^{(112)}$ It is estimated that biofilms account for up to $80 \%$ of microbial infections in the body. Within a biofilm, bacteria display differential gene expression and are upward of 1000 times more resistant to conventional antibiotic treatment. Respiratory and related structures provide ideal environments for the development of bacterial biofilms, which predispose patients to recurrent and chronic infections. Furthermore, biofilms modify themselves following exposure to antimicrobial therapy, thus developing increased resistance. Understanding the nature of biofilms is essential to comprehending the expected course of bacterial illness and identifying treatments that are most likely to be beneficial against more resistant biofilms. ${ }^{(113)}$ A recent study suggests that inhaled antibiotics can be formulated with lipids to improve their penetration of Pseudomonas biofilms following inhalation. $^{(114)}$

Fluid filled lungs-pneumonias and acute lung injury (ALI). The filling of parts of the lungs with fluid is a challenging situation in aerosol medicine. Pneumonias, of which there are many different types, and acute lung injury can be lethal. Pneumonias are a leading cause of death worldwide. Inhaled therapeutics may not reach the fluid filled areas but they could prevent further fluid spread and protect the remaining aerated regions of the lungs. One could argue that although deposition in the diseased area is clearly reduced, it is not zero, and this direct airspace deposition may be a larger dose and more useful than amounts that could reach the diseased area via the vasculature (John Godleski, personal communication). The pioneering work of Smaldone, Palmer, and colleagues ${ }^{(99)}$ has shown that inhaled antibiotics in conjunction with systemic antibiotics, compared with systemic antibiotics alone, has significantly improved efficacy against serious pulmonary infections in the intensive care unit (ICU). How can we harness this approach to thwart the many other types of serious pneumonias?

ALI is a clinical syndrome manifested by a rapid onset of respiratory failure associated with high mortality. ${ }^{(115)}$ ALI is characterized by increased permeability of the alveolarcapillary barrier, decreased surfactant function, and impaired alveolar fluid clearance. Although significant efforts have been made to pharmacologically upregulate alveolar fluid clearance to reverse the progression of lung injury, these approaches have not been successful. ${ }^{(116)}$ However, new results demonstrate a novel role for TGF- $\beta 1$ in impairing the $\beta$-adrenergic agonist stimulated alveolar fluid clearance in acute lung injury, an effect that could be corrected by using PI3K inhibitors that are safe to use in humans. ${ }^{(117)}$ Again there is the question of inhalation versus systemicwhich is better?

Summary. Delivery of drug from both the airway and the blood side would seem to be optimal, and this seems to be a fundamental consideration in regard to the diseases discussed above. When we queried John Godeleski about vascular perfusion in regard to various pulmonary diseases, this was his response: "Although I have not studied the question of vascular perfusion in areas of pulmonary disease, this would be fairly easy to do using modern methods to assess vascular perfusion. One approach can be that used in a paper 
by Glenny et al. ${ }^{(118)}$. We have used this approach in other studies of vascular perfusion and found it to be highly sensitive. Another consideration is that most chronic diseases such as lung fibrosis and emphysema have substantial pulmonary vascular sclerosis in the areas of the disease process. This is readily seen in any human lung pathology specimens with these diseases." So, it is clear that the penetration of aerosol drugs into lung disease tissue and their subsequent efficacy or lack thereof is a wide open field with many opportunities for outstanding work.

\section{An update on nucleotide delivery to the lung}

Gene therapies utilizing modified viruses or complexed plasmid DNA (pDNA) as gene transfer agents (GTAs) to reintroduce functional copies of defective or mutated genes are being investigated for the treatment of a wide range of lung diseases including $\mathrm{CF}$, cancer, and alpha- 1 antitrypsin deficiency. ${ }^{(119)}$ The relative accessibility of the pulmonary epithelium makes aerosol delivery of gene therapy formulations an attractive possibility, allowing noninvasive application to target cells within the lung while minimizing the risks associated with systemic delivery and potential germ line transmission. Despite these advantages, only eight clinical trials (all in patients with cystic fibrosis) have so far incorporated aerosol delivery of GTAs to the lungs as a key component of the study. ${ }^{(120)}$ Encouragingly, partial correction of the underlying CF chloride transport defect was reported in one study, ${ }^{(121)}$ but overall levels of gene expression have been disappointingly low. If aerosol gene therapy is to prove a viable therapeutic option for the treatment of lung diseases in the future, significant improvements in the efficacy of aerosolized GTAs will be required.

Aerosolization of gene transfer agents. Despite considerable advances in gene therapy over the last 20 years, transfer of technological improvements to aerosol gene therapy has been limited by the additional constraints placed upon formulations for nebulization and the associated costs of developing and testing in relevant animal model systems. Consequently, only recombinant adenovirus (Ad), ${ }^{(122)}$ adeno-associated virus (AAV), ${ }^{(123)}$ and pDNA complexed to the cationic lipid Genzyme Lipid 67A (GL67A) ${ }^{(121)}$ have so far advanced to clinical studies. The key factor in limiting the progress of aerosol gene therapies has been the susceptibility of many viral and nonviral formulations to hydrodynamic shear forces associated with many aerosol generation devices. Continuous recycling of material within many nebulizers results in rapid and progressive destruction of shearsensitive molecules including some enveloped viruses ${ }^{(124)}$ and the circular pDNA component of many nonviral gene therapy formulations (Fig. 7). Such destruction is associated with an almost complete loss of biological function, and as a result, only a fraction of the available GTAs have proven viable for aerosol delivery.

To improve the delivery of GTAs, multiple innovations are needed. Improved formulations that protect GTAs during aerosolization as well as nebulization devices that minimize the exposure to hydrodynamic shear would greatly improve the range of GTAs suitable for aerosol applications. There is evidence that with appropriate nebulization devices even highly sensitive molecules such as pDNA can be

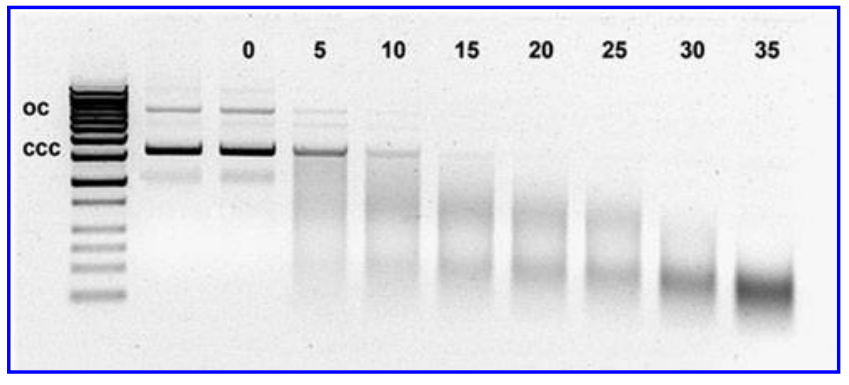

FIG. 7. Degradation of naked pDNA during jet nebulization. Plasmid DNA $(5.6 \mathrm{~kb})$ was aerosolized at 40 psi using the Aerotech II (CIS-US, Bedford, MA) jet nebulizer with samples removed from the reservoir at 5-min intervals for conformational analysis by gel electrophoresis. Aerosolization resulted in progressive degradation of pDNA with loss of both covalently closed circular (ccc) and open circular (oc) plasmid forms. Lane 1, plasmid size markers; lane 2, reference plasmid (not aerosolized); lanes 3-10, plasmid DNA samples following $0-35 \mathrm{~min}$ of aerosolization.

aerosolized successfully. Electrospray of plasmids up to $15.3 \mathrm{~kb}$ in size resulted in no detectable pDNA degradation, and aerosol delivery of such formulations resulted in robust gene expression in the lungs of treated mice. ${ }^{(125)}$ However, no EHD device has yet been commercialized for use in the clinic, and there remain considerable obstacles with regard to formulation compatibility and electrospray requirements.

Barriers to aerosol gene transfer. The general inefficiency of gene transfer following aerosol delivery in animal model systems as well as in clinical studies ${ }^{(126)}$ would suggest that significant barriers to gene transfer exist in the lung. Of the many physical barriers to successful aerosol gene delivery, potentially the most significant is the layer of mucus covering the epithelial cells of the conducting airway. Sequestration of GTAs by mucus or shielding of target cell populations from vector access can greatly reduce the efficacy of aerosolized GTAs, especially in the diseased lung. In diseases such as CF or asthma, the mucus barrier may be thicker and also more hostile, containing greater amounts of active proteases and nucleases, which might degrade essential biological components of delivered GTAs. In such circumstances, it may prove beneficial to reduce the mucus burden of the lungs prior to gene delivery via the use of mucolytic agents such as Nacystelyn. ${ }^{(127)}$ In addition to mucus clearance, pulmonary macrophages can also eliminate delivered GTAs via phagocytosis, and resident macrophages in the mouse lung have been shown to clear $70 \%$ of adenovirus genomes within $24 \mathrm{~h}$ of administration. ${ }^{(28)}$ Removal of macrophages by prior delivery of liposomes incorporating dichloromethylene-biphosphanate resulted in a $96 \%$ increase in adenoviral gene expression, ${ }^{(128)}$ although it is unclear how such an approach could be translated to the clinic. For viral vectors an additional barrier is the presence or generation of neutralizing antibodies (NAbs) to the viral vectors themselves. Exposure to viral GTAs has been shown to generate potent NAbs in a number of animal model systems ${ }^{(129,130)}$ at titers high enough to completely inhibit gene transfer from subsequent treatments. ${ }^{(129)}$ Numerous immunomodulatory approaches have been proposed, ${ }^{(131)}$ but the generation of 
NAbs remains possibly the most significant barrier to successful long-term airway gene transfer using viral vectors. Encouragingly, recent studies utilizing integrating lentiviral vectors have demonstrated that repeated delivery to the mouse nasal epithelium is possible without generation of mucosal anti-lentiviral antibodies. ${ }^{(132)}$ If these results can be translated to the lung, and an appropriate aerosol delivery methodology can be identified then lentiviral vectors may represent an exciting direction for future lung gene therapies.

Animal models. If the efficiency of aerosol gene delivery is to improve dramatically in the coming years it will be essential to identify which of the various barriers to gene transfer are critical for each GTA. However, many of the physical and immunological barriers to aerosol gene delivery are likely to be disease specific. Wherever possible, studies to identify and overcome such barriers should be performed in suitable animal disease models. Historically, the mouse lung has provided the primary model for aerosol gene delivery. However, the difficulties in generating aerosols with appropriate size characteristics, the peculiarities of mouse lung anatomy, and a failure of many transgenic mouse lines to recapitulate human disease phenotypes, ${ }^{(133)}$ have led to a requirement for suitable lung disease models in larger animals. Such models remain elusive, although the recent generation of transgenic pigs homozygous for the most common mutation in cystic fibrosis (deltaF508) ${ }^{(134)}$ will hopefully provide new insight into the critical parameters required for successful aerosol gene delivery in the CF lung.

Summary. Although delivery of gene therapy formulations via aerosols remains a relatively new field, numerous preclinical and clinical studies have demonstrated the potential for aerosol mediated gene transfer in the lung. However, if aerosol gene therapy is to prove to be a viable clinical therapeutic option for the treatment of lung disease, it is clear that significant advances in vector design and performance will be required. Crucial to achieving these goals will be identifying and overcoming critical barriers to efficient gene transfer by aerosolized GTAs-a task that will be best achieved in relevant large animal models of disease with appropriate lung pathology. Finally, to streamline the development of GTAs suitable for aerosol delivery in the future, it is essential that novel GTA formulation development and optimization studies are performed in the context of aerosol delivery from an early stage.

\section{Conclusions}

We are optimistic about the long-term prospect of delivering pharmaceuticals to and through the lung. We have barely scratched the surface of what is possible. Pulmonary delivery, where we achieve high pulmonary concentrations while protecting sensitive organs elsewhere, makes a lot of sense; for example, especially drugs designed to treat lung cancer or pulmonary infections have a good rationale for pulmonary delivery. The lungs are less than $1 \%$ of the body weight. Why put a potent, expensive, toxic drug everywhere in the body when it is only needed in a particular location (in the lung)? Similarly, the potential for systemic drug delivery via the lung continues to make sense. When oral or dermal delivery is not possible (e.g., growth hormone, insulin, erythropoietin), it makes sense to develop an appropriate pulmonary formulation.

Nevertheless, these aspirations will never be realized unless we address the fundamental questions outlined in this article. Where do inhaled drugs deposit? What happens to them after they land? Where and how are they degraded or lost? How can we control and enhance bioavailability? Essential questions are abundant; clever new experimental designs to answer them are few; and the saga continues...

\section{Acknowledgments}

This conference has been made possible through the sponsorship of Novartis Pharmaceuticals and AstraZeneca R\&D. C.E. acknowledges funding by a Strategic Research Cluster Grant (07/SRC/B1154) under the National Development Plan cofunded by EU Structural Funds and Science Foundation Ireland. K.-J.K. acknowledges funding by the Whittier Foundation, Hastings Foundation, and National Institutes of Health. L.A.D. acknowledges funding by the United Kingdom Cystic Fibrosis Gene Therapy Consortium.

\section{Author Disclosure Statement}

No conflicts of interest exist.

\section{References}

1. Brain JD, and Valberg PA: Deposition of aerosol in the respiratory tract. Am Rev Respir Dis. 1979;120:1325-1373.

2. Patton JS, and Byron PR: Inhaling medicines: delivering drugs to the body through the lungs. Nat Rev Drug Discov. 2007;6:67-74.

3. Watson AY, and Brain JD: Uptake of iron-oxide aerosols by mouse airway epithelium. Lab Invest. 1979;40:450-459.

4. Schürch S, Gehr P, Im Hof V, Geiser M, and Green F: Surfactant displaces particles toward the epithelium in airways and alveoli. Respir Physiol. 1990;80:17-32.

5. Leith DE, Butler JP, Sneddon SL, and Brain JD: Cough. In: Macklem PT, Mead J (eds.), Handbook of Physiology, The Respiratory System. American Physiological Society, Bethesda, MD; pp. 315-336, 1986.

6. Widdicombe JG: Airway liquid: a barrier to drug diffusion? Eur Respir J. 1997;10:2194-2197.

7. Edsbäcker S, and Johansson CJ: Airway selectivity: an update of pharmacokinetic factors affecting local and systemic disposition of inhaled steroids. Basic Clin Pharmacol Toxicol. 2006;98:523-536.

8. Sanders NN, De Smedt SC, Van Rompaey E, Simeons P, De Baets F, and Demeester J: Cystic fibrosis sputum-a barrier to the transport of nanospheres. Am J Resp Crit Care Med. 2000;162:1905-1911.

9. Khanvilkar K, Donovan MD, and Flanagan DR: Drug transfer through mucus. Adv Drug Deliv Rev. 2001;48:173-193.

10. Arora D, and Sakagami M: Kinetic assessment of aerosol particle dissolution and membrane permeation for testing commercial inhaler products. AAPS J. 2007;9:W5241.

11. Arora D, and Sakagami M: In vitro lung epithelial cell monolayer-based assessment of anti-inflammatory response of inhaled corticosteroids and deposition: the importance of dissolution. AAPS J. 2008;10:T2169.

12. Tolman JA, and Williams RO: Advances in the pulmonary delivery of poorly water-soluble drugs: influence of solubilization on pharmacokinetic properties. Drug Dev Ind Pharm. [Epub ahead of print]. PMID: 19640248. 
13. Newhouse MT, Hirst PH, Duddu SP, Walter $\mathrm{YH}$, Tarara TE, Clark AR, and Weers JG: Inhalation of a dry powder tobramycin PulmoSphere formulation in healthy volunteers. Chest. 2003;124:360-363.

14. Sakagami M: Insulin disposition in the lung following oral inhalation in humans: a meta-analysis of its pharmacokinetics. Clin Pharmacokinet. 2004;43:539-552.

15. Clark A, Kuo M, Newman S, Hirst P, Pitcairn G, and Pickford M: A comparison of the pulmonary bioavailability of powder and liquid aerosol formulations of salmon calcitonin. Pharm Res. 2008;25:1583-1590.

16. Davies NM, and Feddah MR: A novel method for assessing dissolution of aerosol inhaler products. Int J Pharm. 2003; 255:175-187.

17. Freiwald M, Valotis A, Kirschbaum A, McClellan M, Mürdter T, Fritz P, Friedel G, Thomas M, and Högger $P$ : Monitoring the initial pulmonary absorption of two different beclomethasone dipropionate aerosols employing a human lung reperfusion model. Respir Res. 2005; $6: 21$.

18. Chowhan ZT, and Amaro AA: Pulmonary absorption studies utilizing in situ rat lung model: designing dosage regimen for bronchial delivery of new drug entities. J Pharm Sci. 1976;65:1669-1672.

19. Yang JZ, Young AL, Chiang PC, Thurston A, and Pretzer DK: Fluticasone and budesonide nanosuspensions for pulmonary delivery: preparation, characterization, and pharmacokinetic studies. J Pharm Sci. 2008;97:48694878.

20. Gray VA, Hickey AJ, Balmer P, Davies NM, Dunbar C, Foster TS, Olosson BL, Sakagami M, Shah VP, Smurthwaite MJ, Veranth JM, and Zaidi K: The inhalation ad hoc advisory panel for the USP performance tests of inhalation dosage forms. Pharmacopeial Forum. 2008;34:1068-1074.

21. Sakagami M, Byron PR: Respirable microspheres for inhalation: the potential of manipulating pulmonary disposition for improved therapeutic efficacy. Clin Pharmacokinet. 2005;44:263-277.

22. Oberdörster G, Sharp Z, Atudorei V, Elder A, Gelein R, Lunts A, Kreyling W, and Cox C: Extrapulmonary translocation of ultrafine carbon particles following whole-body inhalation exposure of rats. I Toxicol Environ Health A. 2002;65:1531-1543.

23. Oberdörster G, Ferin J, and Lehnert BE: Correlation between particle size, in vivo particle persistence, and lung injury. Environ Health Perspect. 1994;102:173-179.

24. Geiser M, Rothen-Rutishauser B, Kapp N, Schürch S, Kreyling W, Schulz H, Semmler M, Im Hof V, Heyder J, and Gehr P: Ultrafine particles cross cellular membranes by nonphagocytic mechanisms in lungs and in cultured cells. Environ Health Perspect. 2005;113:1555-1560.

25. Braeckmans K, Peeters L, Sanders NN, De Smedt SC, and Demeester J: Three-dimensional fluorescence recovery after photobleaching with the confocal scanning laser microscope. Biophys J. 2003;85:2240-2252.

25a. Brain J: Inhalation, deposition, and fate of insulin and other therapeutic proteins. Diabetes Technol Ther. 2007;9:S4-S15.

26. Dawson M, Wirtz D, and Hanes J: Enhanced viscoelasticity of human cystic fibrotic sputum correlates with increasing microheterogeneity in particle transport. J Biol Chem. 2003;278:50393-50401.

27. Randall SH, and Boucher RC: Effective mucus clearance is essential for respiratory health. Am J Resp Cell Mol Biol. 2006;35:20-28.
28. Kaliner M, Shelhamer JH, Borson B, Nadel J, Patow C, and Marom Z: Human respiratory mucus. Am Rev Respir Dis. 1986;134:612-621.

29. Schürch S, Geiser M, Lee MM, and Gehr P: Particles at the airway interfaces of the lung. Colloids Surfaces B: Biointerfaces. 1999;15:339-353.

30. Geiser M, Schürch S, and Gehr P: Influence of surface chemistry and topography of particles on their immersion into the lung's surface-lining layer. J Appl Physiol. 2003;94: 1793-1801.

31. Sakagami M, Sakon K, Kinoshita W, and Makino Y: Enhanced pulmonary absorption following aerosol administration of mucoadhesive powder microspheres. J Control Release. 2001;77:117-129.

32. Yamamoto H, Kuno Y, Sugimoto S, Takeuchi H, and Kawashima Y: Surface-modified PLGA nanosphere with chitosan improved pulmonary delivery of calcitonin by mucoadhesion and opening of the intercellular tight junctions. J Control Release. 2005;102:373-381.

33. Sanders NN, Van Rompaey E, De Smedt SC, and Demeester J: On the transport of lipoplexes through cystic fibrosis sputum. Pharm Res. 2002;19:451-456.

34. Carrabino S, Di Gioia S, Copreni E, and Conese M: Serum albumin enhanced polyethyleneimine-mediated gene delivery to human respiratory epithelial cells. J Gene Med. 2005;7:1555-1564.

35. Suk JS, Lai SK, Wang YY, Ensign LM, Zeitlin PL, Boyle $\mathrm{MP}$, and Hanes J: The penetration of fresh undiluted sputum expectorated by cystic fibrosis patients by nonadhesive polymer nanoparticles. Biomaterials. 2009;30: 2591-2597.

36. Patton JS: Mechanisms of macromolecule absorption by the lungs. Adv Drug Deliv Rev. 1996;19:3-36.

37. Kim KJ, and Malik A: Protein transport across the lung epithelial barrier. Am J Physiol. 2003;284:L247-L259.

38. Siekmeier R, and Scheuch G: Inhaled insulin-does it become reality? J Physiol Pharmacol. 2008;59:81-113.

39. Yamahara H, Lehr CM, Lee VH, and Kim KJ: Fate of insulin during transit across rat alveolar epithelial cell monolayers. Eur J Pharm Biopharm. 1994;40:294-298.

40. Bur M, Huwer H, Lehr CM, Hagen N, Guldbrandt M, Kim $\mathrm{KJ}$, and Ehrhardt C: Assessment of transport rates of proteins and peptides across primary human alveolar epithelial cell monolayers. Eur J Pharm Sci. 2006;28:196203.

41. Ducreux J, and Vanbever R: Crucial biopharmaceutical issues facing macromolecular candidates for inhalation: the role of macrophages in pulmonary protein clearance. Respir Drug Deliv Eur. 2007;2007:31-41.

42. Lombry C, Edwards DA, Preat V, and Vanbever R: Alveolar macrophages are a primary barrier to pulmonary absorption of macromolecules. Am J Physiol. 2004;286: L1002-L1008.

43. Berg JT, Lee ST, Thepen T, Lee CY, and Tsan MF: Depletion of alveolar macrophages by liposome-encapsulated dichloromethylene diphosphonate. J Appl Physiol. 1993;74: 2812-2819.

44. Pinto AJ, Stewart D, van Rooijen N, and Morahan PS: Selective depletion of liver and splenic macrophages using liposomes encapsulating the drug dichloromethylene diphosphonate: effects on antimicrobial resistance. J Leukoc Biol. 1991;49:579-586.

45. Kim KJ, Fandy TE, Lee VH, Ann DK, Borok Z, and Crandall ED: Net absorption of IgG via FcRn-mediated trans- 
cytosis across rat alveolar epithelial cell monolayers. Am J Physiol. 2004;287:L616-L622.

46. Allavena P, Chieppa M, Monti P, and Piemonti L: From pattern recognition receptor to regulator of homeostasis: the double-faced macrophage mannose receptor. Crit Rev Immun. 2004;24:179-192.

47. Janeway CA, Travers P, Walport M, Shlomchik MJ: Immunobiology: The Immune System in Health and Disease, 6th ed. Garland Publishing, New York; 2005.

48. Wright JR: Immunomodulatory functions of surfactant. Physiol Rev. 1997;77:931-962.

49. Wikstrom ME, and Stumbles PA: Mouse respiratory tract dendritic cell subsets and the immunological fate of inhaled antigens. Immunol Cell Biol. 2007;85:182-188.

50. Lombry C, Louahed J, Ucakar B, Renauld JC, Preat V, and Vanbever R: Alveolar macrophages inhibit the immune response to pulmonary antigen delivery. J Aerosol Med. 2005;18:114-115.

51. Holt PG: Regulation of immunological homeostasis in the respiratory tract. Nat Rev Immunol. 2008;8:142-152.

52. Chelen CJ, Fang Y, Freeman GJ, Secrist H, Marshall JD, Hwang PT, Frankel LR, DeKruyff RH, and Umetsu DT: Human alveolar macrophages present antigen ineffectively $\mathrm{du}$ the defective expression of B7 costimaultory cell surface molecules. J Clin Invest. 1995;95: 1415-1421.

53. Holt PG, Oliver J, Bilyk N, McMenamin CH, McMenamin PG, Kraal G, and Thepen T: Downregulation of the antigen presenting cell function(s) of pulmonary dendritic cells in vivo by resident alveolar macrophages. J Exp Med. 1993; 177:397-407.

54. Lambrecht BN: Alveolar macrophage in the driver's seat. Immunity. 2006;24:366-368.

55. Reddy ST, Swartz MA, and Hubbell JA: Targeting dendritic cells with biomaterials: developing the next generation of vaccines. Trends Immunol. 2006;27:573-579.

56. Endter S, Francombe D, Ehrhardt C, and Gumbleton M: RT-PCR analysis of ABC, SLC and SLCO drug transporters in human lung epithelial cell models. J Pharm Pharmacol. 2009;61:583-591.

57. Bosquillon C. Drug transporters in the lung-do they play a role in the biopharmaceutics of inhaled drugs? J Pharm Sci [Epub ahead of print] PMID: 19950388.

58. Van der Deen M, de Vries EG, Timens W, Scheper RJ, Timmer-Bosscha $\mathrm{H}$, and Postma DS: ATP-binding cassette (ABC) transporters in normal and pathological lung. Respir Res. 2005;6:59.

59. Gumbleton M, Al-Jayyoussi G, Francombe D, Morris CJ, and Smith MW: Spatial expression and functionality of drug transporters in intact lung: areas for further investigation in pulmonary drug transporter research. J Aerosol Med Pulm Drug Deliv. (in press).

60. Pajeva IK, and Wiese M: Pharmacophore model of drugs involved in P-glycoprotein multidrug resistance: explanation of structural variety (hypothesis). J Med Chem. 2002; 45:5671-5686.

61. Raub TJ: P-glycoprotein recognition of substrates and circumvention through rational drug design. Mol Pharmaceut. 2006;3:3-25.

62. Stouch TR, and Gudmundsson O: Progress in understanding the structure-activity relationships of P-glycoprotein. Adv Drug Deliv Rev. 2002;54:315-328.

63. Brady JM, Cherrington NJ, Hartley DP, Buist SC, Li N, and Klaassen CD: Tissue distribution and chemical induction of multiple drug resistance genes in rats. Drug Metab Dispos. 2002;30:838-844.

64. Campbell L, Abulrob AN, Kandalaft LE, Plummer S, Hollins AJ, Gibbs A, and Gumbleton M: Constitutive expression of p-glycoprotein in normal lung alveolar epithelium and functionality in primary alveolar epithelial cultures. J Pharmacol Exp Ther. 2003;304:441-452.

65. Cordon-Cardo C, O’Brien JP, Boccia J, Casals D, Bertino JR, and Melamed MR: Expression of the multidrug resistance gene product (P-glycoprotein) in human normal and tumor tissues. J Histochem Cytochem. 1990;38:1277-1287.

66. Lechapt-Zalcman E, Hurbain I, Lacave R, Commo F, Urban $\mathrm{T}$, Antoine M, Milleron B, and Bernaudin JF: MDR1-Pgp 170 expression in human bronchus. Eur Respir J. 1997;10:1837-1843.

67. Van der Valk $P$, van Kalken CK, Ketelaars H, Broxterman HJ, Scheffer G, Kuiper CM, Tsuruo T, Lankelma J, Meijer CJ, Pinedo HM, and Scheper RJ: Distribution of multi-drug resistance-associated P-glycoprotein in normal and neoplastic human tissues. Ann Oncol. 1990;1: 56-64.

68. Scheffer GL, Pijnenborg AC, Smit EF, Muller M, Postma DS, Timens W, van der Valk P, de Vries EG, and Scheper RJ: Multidrug resistance related molecules in human and murine lung. J Clin Pathol. 2002;55:332-339.

69. Endter S, Becker U, Daum N, Huwer H, Lehr CM, Gumbleton M, and Ehrhardt C: P-glycoprotein (MDR1) functional activity in human alveolar epithelial cell monolayers. Cell Tissue Res. 2007;328:77-84.

70. Tronde A, Norden B, Marchner H, Wendel AK, Lennernas $\mathrm{H}$, and Bengtsson UH: Pulmonary absorption rate and bioavailability of drugs in vivo in rats: structure-absorption relationships and physicochemical profiling of inhaled drugs. J Pharm Sci. 2003;92:1216-1233.

71. Tronde A, Norden B, Jeppsson AB, Brunmark P, Nilsson E, Lennernas $\mathrm{H}$, and Bengtsson UH: Drug absorption from the isolated perfused rat lung-correlations with drug physicochemical properties and epithelial permeability. I Drug Target. 2003;11:61-74.

72. Manford F, Riffo-Vasquez Y, Spina D, Page CP, Hutt AJ, Moore V, Johansson F, and Forbes B: Lack of difference in pulmonary absorption of digoxin, a P-glycoprotein substrate, in mdr1a-deficient and mdr1a-competent mice. J Pharm Pharmacol. 2008;60:1305-1310.

73. Madlova M, Bosquillon C, Asker D, Dolezal P, and Forbes B: In-vitro respiratory drug absorption models possess nominal functional P-glycoprotein activity. J Pharm Pharmacol. 2009;61:293-301.

74. Francombe D, Taylor G, Taylor S, Somers G, Edwards CD, and Gumbleton M: Functional role of P-gp efflux in limiting pulmonary drug absorption within an intact lung: application of an isolated perfused rat lung model. Respir Drug Deliv. 2008:461-464.

75. Deeley RG, Westlake C, and Cole SP: Transmembrane transport of endo- and xenobiotics by mammalian ATPbinding cassette multidrug resistance proteins. Physiol Rev. 2006;86:849-899.

76. Gradhand U, and Kim RB: Pharmacogenomics of MRP transporters (ABCC1-5) and BCRP (ABCG2). Drug Metab Rev. 2008;40:317-354.

77. Flens MJ, Zaman GJ, van der Valk P, Izquierdo MA, Schroeijers AB, Scheffer GL, van der Groep P, de Haas M, Meijer CJ, and Scheper RJ: Tissue distribution of the multidrug resistance protein. Am J Pathol. 1996;148:1237-1247. 
78. Brechot JM, Hurbain I, Fajac A, Daty N, and Bernaudin JF: Different pattern of MRP localization in ciliated and basal cells from human bronchial epithelium. J Histochem Cytochem. 1998;46:513-517.

79. Robey RW, To KK, Polgar O, Dohse M, Fetsch P, Dean M, and Bates SE: ABCG2: a perspective. Adv Drug Deliv Rev. 2009;61:3-13.

80. Fetsch PA, Abati A, Litman T, Morisaki K, Honjo Y, Mittal $\mathrm{K}$, and Bates SE: Localization of the ABCG2 mitoxantrone resistance-associated protein in normal tissues. Cancer Lett. 2006;235:84-92.

81. Koepsell H, Lips K, and Volk C: Polyspecific organic cation transporters: structure, function, physiological roles, and biopharmaceutical implications. Pharm Res. 2007;24:12271251.

82. Lips KS, Volk C, Schmitt BM, Pfeil U, Arndt P, Miska D, Ermert L, Kummer W, and Koepsell H: Polyspecific cation transporters mediate luminal release of acetylcholine from bronchial epithelium. Am J Respir Cell Mol Biol. 2005;33:79-88.

83. Horvath G, Schmid N, Fragoso MA, Schmid A, Conner GE, Salathe $\mathrm{M}$, and Wanner A: Epithelial organic cation transporters ensure $\mathrm{pH}$-dependent drug absorption in the airway. Am J Respir Cell Mol Biol. 2007;36:53-60.

84. Nakamura T, Nakanishi T, Haruta T, Shirasaka Y, Keogh JP, and Tamai I: Transport of ipratropium, an anti-chronic obstructive pulmonary disease (COPD) drug, is mediated by organic cation/carnitine transporters in human bronchial epithelial cells: implications for carrier-mediated pulmonary absorption. Mol Pharm. 2010;7:187-195.

85. Ehrhardt C, Kneuer C, Bies C, Lehr CM, Kim KJ, and Bakowsky U: Salbutamol is actively absorbed across human bronchial epithelial cell layers. Pulm Pharmacol Ther. 2005;18:165-170.

86. Anzai N, Kanai Y, and Endou H: Organic anion transporter family: current knowledge. J Pharmacol Sci. 2006;100:411426.

87. Bleasby K, Castle JC, Roberts CJ, Cheng C, Bailey WJ, Sina JF, Kulkarni AV, Hafey MJ, Evers R, Johnson JM, Ulrich RG, and Slatter JG: Expression profiles of 50 xenobiotic transporter genes in humans and pre-clinical species: a resource for investigations into drug disposition. Xenobiotica. 2006;36:963-988.

88. Hagenbuch B, and Meier PJ: The superfamily of organic anion transporting polypeptides. Biochim Biophys Acta. 2003;1609:1-18.

89. Tamai I, Nezu J, Uchino H, Sai Y, Oku A, Shimane M, and Tsuji A: Molecular identification and characterization of novel members of the human organic anion transporter (OATP) family. Biochem Biophys Res Commun. 2000;273:251-260.

90. Groneberg DA, Eynott PR, Doring F, Dinh QT, Oates T, Barnes PJ, Chung KF, Daniel H, and Fischer A: Distribution and function of the peptide transporter PEPT2 in normal and cystic fibrosis human lung. Thorax. 2002;57:55-60.

91. Scheuch G, and Siekmeier R: Novel approaches to enhance pulmonary delivery of peptides and proteins. J Physiol Pharmacol. 2007;58:615-625.

92. Patton JS, Bukar JG, and Eldon MA: Clinical pharmacokinetics and pharmacodynamics of inhaled insulin. Clin Pharmacokinet. 2004;43:781-801.

93. Sweeney TD, Brain JD, Tryka AF, and Godleski JJ: Deposition of particles in hamsters with pulmonary fibrosis. Am Rev Respir Dis. 1983;128:138-143.
94. Sweeney TD, Brain JD, Leavitt SA, and Godleski JJ: Emphysema alters the deposition pattern of inhaled particles in hamsters. Am J Pathol. 1987;128:19-28.

95. Sweeney TD, Skornik WA , Brain JD, Hatch V, and Godleski JJ: Chronic bronchitis alters the pattern of deposition in the lung. Am J Respir Crit Care Med. 1995;151:482-488.

96. Brain JD, Sweeney TD, Tryka AF, Skornik WA, and Godleski JJ: Effects of pulmonary fibrosis on aerosol deposition in hamsters. J Aerosol Sci. 1984;15:217-218.

97. Tryka AF, Sweeney TD, Brain JD, and Godleski JJ: Pulmonary fibrosis alters short-term clearance of an inhaled submicrometric aerosol. Am Rev Respir Dis. 1985;132:606-611.

98. Bondesson E, Bengtsson T, Nilsson LE, and Wollmer P: Site of deposition and absorption of inhaled hydrophilic solutes. Respir Drug Deliv. 2006;461-464.

99. Palmer LB, Smaldone GC, Chen JJ, Baram DM, Duan T, Monteforte M, Varela M, Tempone MK, O'Riordan T, Daroowalla F, and Richman P: Aerosolized antibiotics and ventilator-associated tracheobronchitis in the intensive care unit. Crit Care Med. 2008;36:2008-2013.

100. Petersen AH, Kohler G, Korsatko S, Wutte A, Wonisch M, Mautner A, Ronn BB, Clauson P, Laursen T, Wollmer P, and Pieber TR: The effect of exercise on the absorption of inhaled human insulin in healthy volunteers. Br J Clin Pharmacol. 2008;65:165-171.

101. Ebina M, Shimizukawa M, Shibata N, Kimura Y, Suzuki T, Endo M, Sasano H, Kondo T, and Nukiwa T: Heterogeneous increase in CD34-positive alveolar capillaries in idiopathic pulmonary fibrosis. Am J Respir Crit Care Med. 2004;169:1203-1208.

102. Souza CA, Muller NL, Flint J, Wright JL, and Churg A: Idiopathic pulmonary fibrosis: spectrum of high-resolution CT findings. Am J Roentgenol. 2005;185:1531-1539.

103. Gaine S: Pulmonary hypertension. JAMA. 2000;284:31603168.

104. McGoon MD, and Kane GC: Pulmonary hypertension: diagnosis and management. Mayo Clin Proc. 2009;84:191-207.

105. Rai PR, Cool CD, King JA, Stevens T, Burns N, Winn RA, Kasper M, and Voelkel NF: The cancer paradigm of severe pulmonary arterial hypertension. Am J Respir Crit Care Med. 2008;178:558-564.

106. Krug S, Sablotzki A, Hammerschmidt S, Wirtz H, and Seyfarth HJ: Inhaled iloprost for the control of pulmonary hypertension. Vasc Health Risk Manage. 2009;5: 465-474.

107. Godoy MC, and Naidich DP: Review: subsolid pulmonary nodules and the spectrum of peripheral adenocarcinomas of the lung: recommended interim guidelines for assessment and management. Radiology. 2009;253:606-622.

108. Latimer P, Menchaca M, Snyder RM, Yu W, Gilbert BE, Sanders BG, and Kline K: Aerosol delivery of liposomal formulated paclitaxel and vitamin $\mathrm{E}$ analog reduces murine mammary tumor burden and metastases. Exp Biol Med. 2009;234:1244-1252.

109. Bosch F, and Rosich L: The contributions of Paul Ehrlich to pharmacology: a tribute on the occasion of the centenary of his Nobel Prize. Pharmacology. 2008;82:171-179.

110. Maeda H, Bharate GY, and Daruwalla J: Polymeric drugs for efficient tumor-targeted drug delivery based on EPReffect. Eur J Pharm Biopharmacol. 2009;71:409-419.

111. Wei YH, Xu LZ, Shen Q, and Li FZ: Microdialysis: a technique for pharmacokinetic-pharmacodynamic studies of oncological drugs. Curr Pharm Biotechnol. 2009;10:631640 . 
112. Kobayashi H: Airway biofilms: Implications for pathogenesis and therapy of respiratory tract infections. Treat Respir Med. 2005;4:241-253.

113. Liu YC, and Post JC: Biofilms in pediatric respiratory and related infections. Curr Allergy Asthma Rep. 2009;9:449-455.

114. Meers P, Neville M, Malinin V, Scotto AW, Sardaryan G, Kurumunda R, Mackinson C, James G, Fisher S, and Perkins WR: Biofilm penetration, triggered release and in vivo activity of inhaled liposomal amikacin in chronic Pseudomonas aeruginosa lung infections. J Antimicrob Chemother. 2008;61:859-868.

115. Rubenfeld GD, Caldwell E, Peabody E, Weaver J, Martin DP, Neff M, Stern EJ, and Hudson LD: Incidence and outcomes of acute lung injury. N Engl J Med. 2005;353:1685-1693.

116. Calfee CS, and Matthay MA: Nonventilatory treatments for acute lung injury and ARDS. Chest. 2007;131:913-920.

117. Roux J, Carles M, Koh H, Goolaerts A, Ganter MT, Chesebro BB, Howard M, Houseman BT, Finkbeiner W, Shokat KM, Paquet AC, Matthay MA, and Pittet JF: TGF-\{beta\}1 inhibits CFTR-dependent cAMP-stimulated alveolar epithelial fluid transport via a PI3K-dependent mechanism. J Biol Chem. 2009 [Epub ahead of print] PMID: 19996317.

118. Glenny RW, Bernard SL, and Lamm WJ: Hemodynamic effects of 15-micron diameter microspheres on the rat pulmonary circulation. J Appl Physiol. 2000;89:499-504.

119. Gill DR, Davies LA, Pringle IA, and Hyde SC: The development of gene therapy for diseases of the lung. Cell Mol Life Sci. 2004;61:355-368.

120. Griesenbach U, and Alton EW: Gene transfer to the lung: lessons learned from more than 2 decades of CF gene therapy. Adv Drug Deliv Rev. 2009;61:128-139.

121. Alton EW, Stern M, Farley R, Jaffe A, Chadwick SL, Phillips J, Davies J, Smith SN, Browning J, Davies MG, Hodson ME, Durham SR, Li D, Jeffery PK, Scallan M, Balfour R, Eastman SJ, Cheng SH, Smith AE, Meeker D, and Geddes DM: Cationic lipid-mediated CFTR gene transfer to the lungs and nose of patients with cystic fibrosis: a double-blind placebo-controlled trial. Lancet. 1999;353:947-954.

122. Perricone MA, Morris JE, Pavelka K, Plog MS, O'Sullivan BP, Joseph PM, Dorkin H, Lapey A, Balfour R, Meeker DP, Smith AE, Wadsworth SC, St George JA: Aerosol and lobar administration of a recombinant adenovirus to individuals with cystic fibrosis. II. Transfection efficiency in airway epithelium. Hum Gene Ther. 2001;12:1383-1394.

123. Moss RB, Milla C, Colombo J, Accurso F, Zeitlin PL, Clancy JP, Spencer LT, Pilewski J, Waltz DA, Dorkin HL, Ferkol T, Pian M, Ramsey B, Carter BJ, Martin DB, and Heald AE: Repeated aerosolized AAV-CFTR for treatment of cystic fibrosis: a randomized placebo-controlled phase $2 \mathrm{~B}$ trial. Hum Gene Ther. 2007;18:726-732.

124. Coates AL, Tipples G, Leung K, Gray M, and Louca E: How many infective viral particles are necessary for successful mass measles immunization by aerosol? Vaccine. 2006;24: 1578-1585.

125. Davies LA, Hannavy K, Davies N, Pirrie A, Coffee RA, Hyde SC, and Gill DR: Electrohydrodynamic comminution: a novel technique for the aerosolisation of plasmid DNA. Pharm Res. 2005;22:1294-1304.

126. Rochat T, and Morris MA: Gene therapy for cystic fibrosis by means of aerosol. J Aerosol Med. 2002;15:229-235.

127. McLachlan G, Baker A, Tennant P, Gordon C, Vrettou C, Renwick L, Blundell R, Cheng SH, Scheule RK, Davies L,
Painter H, Coles RL, Lawton AE, Marriott C, Gill DR, Hyde SC, Griesenbach U, Alton EW, Boyd AC, Porteous DJ, and Collie DD: Optimizing aerosol gene delivery and expression in the ovine lung. Mol Ther. 2007;15:348-354.

128. Worgall S, Leopold PL, Wolff G, Ferris B, Van Roijen N, and Crystal RG: Role of alveolar macrophages in rapid elimination of adenovirus vectors administered to the epithelial surface of the respiratory tract. Hum Gene Ther. 1997;8:1675-1684.

129. Sumner-Jones SG, Gill DR, and Hyde SC: Lack of repeat transduction by recombinant adeno-associated virus type 5/5 vectors in the mouse airway. J Virol. 2007;81:1236012367.

130. Van Ginkel FW, Liu C, Simecka JW, Dong JY, Greenway T, Frizzell RA, Kiyono H, McGhee JR, and Pascual DW: Intratracheal gene delivery with adenoviral vector induces elevated systemic IgG and mucosal IgA antibodies to adenovirus and beta-galactosidase. Hum Gene Ther. 1995;6:895-903.

131. Sinn PL, Burnight ER, and McCray PB: Progress and prospects: prospects of repeated pulmonary administration of viral vectors. Gene Ther. 2009;16:1059-1065.

132. Sinn PL, Arias AC, Brogden KA, and McCray PB: Lentivirus vector can be readministered to nasal epithelia without blocking immune responses. J Virol. 2008;82:10684-10692.

133. Dorin JR: Development of mouse models for cystic fibrosis. J Inherit Metab Dis. 1995;18:495-500.

134. Rogers CS, Stoltz DA, Meyerholz DK, Ostedgaard LS, Rokhlina T, Taft PJ, Rogan MP, Pezzulo AA, Karp PH, Itani OA, Kabel AC, Wohlford-Lenane CL, Davis GJ, Hanfland RA, Smith TL, Samuel M, Wax D, Murphy CN, Rieke A, Whitworth K, Uc A, Starner TD, Brogden KA, Shilyansky J, McCray PB, Zabner J, Prather RS, and Welsh MJ: Disruption of the CFTR gene produces a model of cystic fibrosis in newborn pigs. Science. 2008;321:18371841.

135. Xia W, Pinto CE, and Kradin RL: The antigen-presenting activities of Ia+dendritic cells shift dynamically from lung to lymph node after and airway challenge with soluble antigen. J Exp Med. 1995;181:1275-1283.

Received on June 9, 2010 in final form, June 14, 2010

Address correspondence to: Dr. John S. Patton Dance Pharmaceuticals 2 Mint Plaza, Suite 804 San Francisco, CA 94103

E-mail: jpatton@dancepharma.com

or

Dr. Carsten Ehrhardt School of Pharmacy and Pharmaceutical Sciences Trinity College Dublin Panoz Institute Dublin 2, Ireland

E-mail: ehrhardc@tcd.ie 
